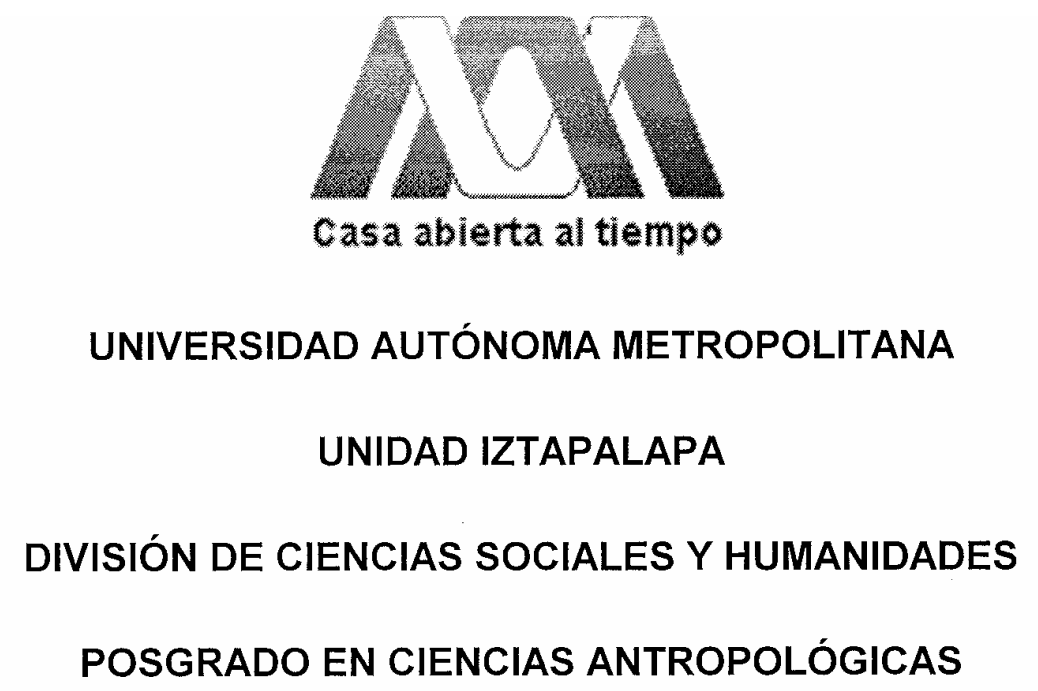

Construcción de espacios políticos en organizaciones

Indígenas del Distrito Federal

Norma Angélica Jaramillo Puebla

Tesina de Maestría en Ciencias Antropológicas

Director: Dra. Angela Giglia Ciotta

Asesores: Dr. Héctor Tejera Gaona

Dr. Daniel Hiernaux-Nicolas 


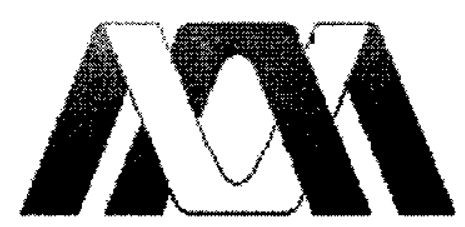

Casa abierta al tiempo

UNIVERSIDAD AUTÓNOMA METROPOLITANA

UNIDAD IZTAPALAPA

DIVISIÓN DE CIENCIAS SOCIALES Y HUMANIDADES

POSGRADO EN CIENCIAS ANTROPOLÓGICAS

\author{
Construcción de espacios políticos en organizaciones \\ Indígenas del Distrito Federal
}

Norma Angélica Jaramillo Puebla

Tesina de Maestría en Ciencias Antropológicas

Director: Dra. Angela Giglia Ciotta

Asesores: Dr. Héctor Tejera Gaona

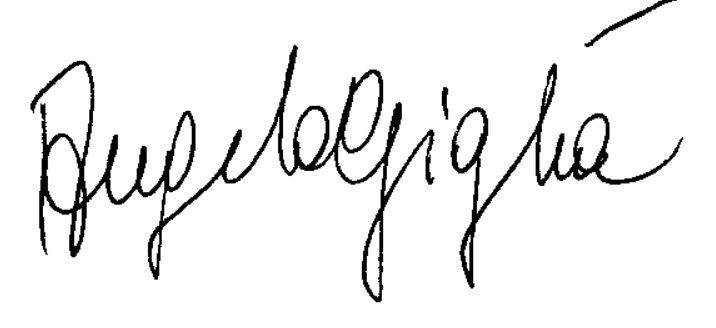

Dr. Daniel Hiernaux-Nicolas 


\section{ÍNDICE}

\section{Introducción}

\section{Ciudadanía}

2. Cultura

2.1 Problemáticas de la cultura en la antropología

2.2 Cultura en movimiento

14

2.3 Cultura y relaciones sociales

\section{Identidad étnica}

3.1 Identidad y cultura

3.2 Identidad y etnia

3.3 Identidad social e identidad étnica

3.5 La identidad como estrategia

\section{Construcción de espacios políticos} en organizaciones indígenas del DF

4.1 Contexto social de investigación

\section{Conclusiones}

5.1 Relaciones interétnicas y construcción de la identidad 


\section{Introducción}

El objeto del presente trabajo es el estudio de las identidades étnicas y su incidencia en las formas de ejercer la ciudadanía. Específicamente, me interesa analizar ¿cuáles son las estrategias ${ }^{1}$ utilizadas en la construcción de los espacios políticos ${ }^{2}$ ¿cómo influyen las pertenencias étnicas en la participación política? ${ }^{3}$ Estas preguntas se pretenden responder a partir del estudio de la relación entre organizaciones indígenas en el Distrito Federal (DF) y las instancias gubernamentales, específicamente, el Consejo de Consulta y Participación Indígena del DF. Consejo consultivo creado por el Gobierno del Distrito Federal, como parte de la Dirección General de Equidad y Desarrollo Social de la Secretaría de Desarrollo Social del DF.

Sobre el papel que juega este consejo y el tipo de respuesta que genera entre la población a la que está dirigido, es que este trabajo encontrará un buen medio para tratar de dilucidar la forma en que una autoridad del DF trata el fenómeno de la presencia indígena y, de igual manera, se podrá conocer cómo los distintos grupos indígenas intentan abrir espacios de actividad política en un terreno donde compiten por obtener ciertos beneficios. El estudio sobre la relación que entablan ambos actores se considera importante porque a partir de ahí se puede conocer si existen las condiciones necesarias que permitan ejercer la ciudadanía y, de igual manera, es posible desentrañar la forma en que la identidad étnica atraviesa dicha relación.

\footnotetext{
1 Estrategias entendidas como la manipulación simbólica que persigue determinar las representaciones sociales que un grupo se forma con respecto a otro. (Giménez, 1987:475) Las manipulaciones pueden ser elecciones conscientes de grupos de personas con el propósito de alcanzar ciertos objetivos sociales. (Baud, 1996:7)

${ }^{2}$ El sentido y la razón de los espacios políticos puede ser dividido en dos aspectos: primero, donde se expresan y se articulan los antagonismos. El segundo, donde se dirimen los distintos intereses y conflictos existentes en una sociedad, sin apelar al recurso de la violencia.

${ }^{3}$ La expresión de participación política generalmente se ha utilizado para designar actividades como: acto de votar, militancia en un partido, participación en manifestaciones, etc. El sentido que se le da aquí es la de aquellas actividades encaminadas a la búsqueda de la apertura de espacios de representación política con el propósito de incidir en las decisiones y acciones gubernamentales.
} 
El estudio de las identidades étnicas y la ciudadanía se pretende realizar por medio del análisis de la construcción de espacios políticos de dos organizaciones indígenas en el DF. A través del estudio de la construcción de los espacios políticos se puede conocer la forma en que se edifican las identidades étnicas y cómo éstas afectan las percepciones, actitudes y prácticas políticas. Los espacios políticos son considerados como el ámbito de lo público donde se definen los rumbos de la vivencia colectiva (bien común) y, al mismo tiempo, donde también se expresa la diferencia ya que es ahí donde los distintos grupos étnicos ${ }^{4}$ que conforman una sociedad ${ }^{5}$ se organizan y participan de acuerdo a sus pertenencias, es decir, donde se articulan la cultura y la política. ${ }^{6}$ En este sentido no se considera un espacio neutro en el que se enfrentan intereses en competencia, se trata de un espacio cuya formación es expresión de relaciones de poder. (Mouffe, 1999: 24)

Consideramos que, ante la indudable presencia indígena en el DF, se requiere conocer las características de su integración y, concretamente para el caso que nos ocupa, qué papel está jugando en el ámbito político. El objetivo central es investigar sobre los mecanismos de acción política, las relaciones sociales y conflictos que se generan cuando se está en la búsqueda y defensa de espacios de participación política.

Para responder los cuestionamientos antes planteados nos hemos centrado en el estudio de las organizaciones indígenas debido a que su simple existencia nos muestra un deseo de

\footnotetext{
${ }^{4}$ Grupo étnico es entendido como una forma de organización social en la que los actores involucrados utilizan categorías de adscripción y autoadscripción, que los identifique a sí mismos y los diferencie de los otros, con fines de interacción (Barth, 1976:15). Igualmente, se le considera como sinónimo de etnia ya que esta comprende un conjunto social que ha desarrollado una fuerte solidaridad o identidad social enfatizando determinados componentes étnicos (formas específicas de interrelación, ciertas características culturales, sistemas de organización social, costumbres y normas comunes, pautas de conducta, lengua, tradición histórica, etc) (Díaz-Polanco, 1988).

5 El término sociedad es entendida como un sistema social dentro del cual convergen grupos con características organizativas diferentes. (Barth: 1976:9)

${ }^{6}$ En este sentido, retomando las ideas de Melucci (1999) y Mouffe (1999), política se considera como el espacio donde se enfrenta y dirimen los antagonismos producto de las diferencias entre los actores o grupos que se enfrentan o convergen en la búsqueda de determinados intereses. Se considera que sin antagonismos no hay política. La política conlleva relaciones antagónicas y de poder (Mouffe, 1999:29). Según Weber, neutralizar los antagonismos significa neutralizar a la propia política ya que en la política, vista como la aspiración a participar e influir en la distribución del poder, la acción social estará condicionada por los intereses o fines de los actores sociales (Weber, 1967:84). Por lo que, los espacios políticos son un terreno donde se puede observar cómo se ponen de manifiesto los antagonismo entre distintos grupos que se enfrentan por objetivos o intereses diversos, los cuales en ocasiones no están predeterminados y van tomando forma o van siendo corregidos de acuerdo al curso que van tomando esas luchas.
} 
participación y representan una evidencia de que los indígenas perciben una mayor aceptación de su etnicidad y, por ende, se atreven a reconocer su identidad y a expresarla públicamente frente a la población no indígena de las ciudades (Hiernaux-Nicolas, 2000: 98). Además, al analizar las relaciones que entablan grupos que conviven cotidianamente en un mismo espacio social, y enfocarnos en el estudio de la influencia que ejerce la identidad en los procesos de participación política; las organizaciones indígenas nos permiten conocer cómo, en el intento por lograr sus objetivos y satisfacer sus intereses, se construyen discursos y categorías tanto de sí mismos como de los grupos a los cuales se enfrentan.

No se puede dejar de reconocer que en nuestra sociedad el poder y la influencia han estado distribuidos desigualmente y que, aunque formalmente todos los ciudadanos sean iguales ante la ley, no todos los grupos sociales gozan de la misma posición y ventajas. Tomado en consideración que esta situación ha sido una fuente importante de conflictos, este trabajo trata de dar a conocer la forma en que determinados sujetos sociales, en este caso grupos étnicos, históricamente carentes de dicho poder, buscan fuentes de acceso que les permita influir en la vida política e institucional de la sociedad que los engloba. La hipótesis que se sostiene en este trabajo es que los miembros de las organizaciones indígenas construyen un conjunto de representaciones, utilizando determinados símbolos culturales, que les sirvan para justificar sus reclamos frente a las autoridades y así lograr cambios a su favor; entonces, en la construcción de los espacios políticos, la exaltación de la diferencia étnica se convierte en un medio para la defensa de intereses muy concretos.

Los espacios políticos representan un campo de proyecciones políticas, es ahí donde los antagonismos entre los distintos grupos se ven reflejados y donde las diversas opiniones, intereses y conflictos pueden ser negociados dependiendo del tipo de relación que entablen entre sí los actores involucrados. En este sentido, para entender el carácter y contenidos de estas relaciones se requiere el análisis de conceptos tales como: ciudadanía, cultura e identidad, ya que son los elementos que, en el fondo de dicha relación, están definiendo las reglas de acción colectiva. Por medio del estudio de las nociones de cultura e identidad se puede conocer cómo se están articulando y conformando estos antagonismos. 
En cuanto a la metodología, inicialmente se había planteado un estudio comparativo entre el DF y los dos municipios del Estado de México con mayor población indígena: Nezahualcoyotl y Chimalhuacán. Pero los primeros acercamientos con las organizaciones indígenas ubicadas en dichos municipios nos revelaron que, debido al tipo de labores que realizan, existe escasa relación entre éstas y las autoridades del Estado de México. Sus labores están ubicadas en el centro de la ciudad por lo cual mantienen mayor relación con las autoridades del DF. ${ }^{7}$ Esto nos llevó a centrarnos en dos organizaciones que habitan en los municipios de Chimalhuacán pero que sus demandas, gestiones y demás trámites los realizan en el DF.

Otro motivo por el cual decidimos centrarnos en el DF es el hecho de que en los municipios antes mencionados no existen los espacios adecuados donde se pueda observar la relación entre organizaciones indígenas y autoridades. En el caso de Nezahualcoyotl no cuentan con ningún espacio formal de atención a la población indígena. Por su lado, Chimalhucán, aunque cuenta con un "Departamento de Asuntos Indígenas", este carece de información acerca de la población indígena que habita en el Municipio, por lo que la relación se puede considerar prácticamente nula. Finalmente, como este trabajo está enfocado al estudio de la relación entre autoridades de gobierno y organizaciones indígenas, se consideró que el DF, al contar con un espacio formal, en este caso el Consejo de Consulta y Participación Indígena, permite la observación de dicha relación y, por ende, es el más apropiado para realizar la investigación.

\footnotetext{
${ }^{7}$ Incluso se encontraron casos de organizaciones que, a pesar de que sus integrantes habitan municipios del Estado de México (Los Reyes La Paz y Ecatepec), sus gestiones las realizan en el DF. Los motivos por los cuales no acuden con sus respectivas autoridades tienen que ver con el hecho de que el costo y el tiempo invertido es mayor ya que, al no contar con algún tipo de apoyo en sus municipios, tienen que desplazarse hasta Toluca.
} 


\section{Ciudadanía}

Para el estudio de la construcción de espacios políticos se retoma el estudio de la ciudadanía. El tipo de ciudadanía que aquí se pretende abordar no es simplemente aquella considerada como un status legal definido por un conjunto de derechos y responsabilidades, sino también aquella que involucra una identidad grupal o es expresión de la pertenencia a una comunidad. Tomando en consideración estos antecedente, podremos analizar cómo el sentido de pertenencia comunitaria influye en la búsqueda de espacios políticos donde los distintos grupos logren reconocimiento y puedan participar abiertamente.

Por medio del análisis de los elementos que la definen se podrá observar las formas y contenidos de la participación política efectuada por comunidades con aspectos culturales muy particulares entre los que se pueden mencionar: un territorio históricamente propio y formas particulares de aprovechamiento de los recursos, lengua indígena, producción de autoconsumo y mercado de excedentes, organización política, ceremonial, social y tradicional, vestimenta propia, producción artesanal, medicina tradicional, alimentación y religión entre otros (Bonfil, 1987). Considerando que la presencia de estos aspectos determinan la actitud y estilos de vida (Arizpe, 1975), se entiende que las características propias de estos grupos también generan formas distintas de participación debido a que ésta estará mediada por su identidad y formas particulares de organización.

Jurídicamente, se considera ciudadano a quienes nacen dentro del territorio del Estado y llegan a la mayoría de edad. En estos términos, la ciudadanía establece una igualdad político-formal ante la ley y ante el Estado. Pero este concepto omite la existencia de grupos de población con expresiones culturales diversas que se encuentran en condiciones de subordinación razón por la cual carecen de las mismas oportunidades de igualdad en el campo político, económico y cultural frente a una sociedad nacional. 
Por otro lado, según Chantal Mouffe, lo que define a un ciudadano es el reconocimiento de un conjunto de principios políticos, "ser un ciudadano es reconocer la autoridad de tales principios y las reglas en las que se encarnan, hacer que sean ellos los que den forma a nuestros juicios y a nuestras acciones...El mismo implica no considerar a la ciudadanía como un status legal, sino como forma de identificación, un tipo de identidad política: algo a construir, no dado empíricamente" (Mouffe, 1999: 96)

Siguiendo las definiciones arriba mencionadas, el estudio que aquí se propone abarca dos campos. El primero tiene que ver con los derechos y responsabilidades de los ciudadanos; y el segundo, con la pertenencia comunitaria y la identificación de aquellos elementos identitarios que permean la participación ciudadana.

Para el primer campo se estudiará el papel que están desempeñando tanto las instituciones de gobierno como los propios ciudadanos en el fortalecimiento de una verdadera ciudadanía. En lo que se refiere a los derechos de los ciudadanos, se considera que el gobierno tiene la obligación de crear los mecanismo necesarios que permitan a cada miembro de la sociedad ser tratado de la misma forma. Este debe garantizar que los derechos civiles, políticos y sociales no sean limitados o violados para evitar que la gente sea marginada o quede incapacitada para participar. Considerando que "sólo es apropiado exigir el cumplimiento de las responsabilidades una vez que se han asegurado los derechos de participación"(Kymlicka y Wayne, 1997). En esta parte se analizará el papel que está cumpliendo el Consejo de Consulta y Participación Indígena del DF como un medio para fomentar la participación.

Considerando que la ciudadanía requiere de un equilibrio entre derechos y responsabilidades, dentro de la obtención de derechos y el cumplimiento de las

\footnotetext{
${ }^{8}$ Estos principios están fundamentados en la idea de igualdad y libertad. Estos principios están encaminados a indicar que más que sacrificar el bien individual en nombre del bien común, debe existir la posibilidad para expresar y sean reconocidas las diferencias y, al mismo tiempo, que todos acepten el carácter particular y limitado de sus reivindicaciones. "una vez que los ciudadanos se ven a sí mismos como libres e iguales, debieran reconocer que para perseguir sus concepciones diferentes del bien necesitan los mismos bienes primarios, es decir, los mismos derechos, libertades y oportunidades básicos, así como los mismos medios para todos los fines, tales como ingreso, riqueza y las mismas bases sociales de autorrespeto." (Rawls, 1985 cit. en Mouffe, 1999:69)
} 
obligaciones debe existir un verdadero compromiso por parte del ciudadano. Para que las personas no se conviertan en entes apáticos y se alimenten, por un lado, procesos clientelares o, por otro lado, un Estado con acciones paternalistas; en la exigencia del cumplimiento de sus derechos debe estar también el interés y la obligación de participar y trabajar por el bien común.

La ciudadanía depende de las cualidades y actitudes de las personas, cualidades que tienen que ver con el compromiso de participar en la vida política con el firme propósito de promover el bien común y tener presente que la defensa de los intereses comunes están más allá de las circunstancias personales. En este sentido se intenta estudiar "la ciudadanía como actividad deseable" que implica que la calidad de la ciudadanía depende de la existencia de un compromiso para participar en todas aquellas actividades que reditúen en un bien común; cooperación y autocontrol en el ejercicio del poder privado (Kymlicka y Wayne, 1997).

Considerando que los elementos de "una ciudadanía deseable" son el compromiso, la cooperación y el autocontrol, según Kymlicka y Wayne "es en las organizaciones voluntarias de la sociedad civil......organizaciones étnicas... donde aprendemos las virtudes del compromiso mutuo". En el caso que pretendemos estudiar, dado que los miembros de las organizaciones indígenas se reúnen voluntariamente, son un buen medio para conocer las motivaciones o intereses de las personas que participan en éstas. Es aquí donde podemos comprobar la existencia de los elementos de la ciudadanía arriba mencionados. Estas organizaciones nos permitirán observar entre sus miembros la idea de responsabilidad personal, compromiso mutuo y autocontrol voluntario, esenciales para ejercer una ciudadanía deseable.

Al mismo tiempo en este trabajo se sostiene que, si bien las organizaciones pueden ser un vehículo para ejercer una ciudadanía deseable, no es esta su única razón de ser. El motivo por el cual muchas veces la gente se incorpora a estas organizaciones no es el participar en el bien común. En ocasiones sus objetivos están encaminados a defender intereses muy específicos por medio de la puesta en práctica de ciertos valores particulares y de grupo, y 
esto puede tener poco que ver con la promoción de la ciudadanía. Por lo que, en el estudio de la ciudadanía, es un aspecto importante que nos obliga a considerar qué tanto están influyendo los discursos e intereses particulares en el tipo de ciudadanía que se ejerce.

Lo anterior nos sirve para enfocarnos en el segundo campo en que estará dividida esta investigación y que tiene que ver con la idea de pertenencia comunitaria. La ciudadanía al promover la defensa de intereses comunes implica un sentido de pertenencia comunitaria (identidad ciudadana) y de propósitos compartidos, por lo que implica también la existencia de un vínculo con una comunidad particular (Mouffe, 1999). Se dice que la ciudadanía es una identidad común, compartida por los individuos independientemente de sus pertenencias grupales. En teoría esto debería ser así ya que la ciudadanía es trabajar por el bienestar común haciendo a un lado los intereses particulares. Pero esto es difícil de sostener cuando nos encontramos en un espacio donde cohabitan grupos culturalmente diferentes. Es aquí donde observamos cómo cada grupo participará en función de los intereses de su comunidad o grupo particular.

Si la ciudadanía implica que los individuos tienen igualdad de derechos ante la ley, cómo las instituciones de gobierno incluirán a los miembros de grupos con características y necesidades diferentes. En el caso que aquí se estudia este es un aspecto que se debe considerar ya que los grupos indígenas, quienes poseen los mismos derechos como ciudadanos, requieren de políticas especiales que eviten su exclusión en el ámbito político, económico, social y cultural. El papel del gobierno será el de proveer los medios institucionales para su reconocimiento y representación en los procesos de decisión política del conjunto de la sociedad, y buscar los medios por los cuales puedan ser incluidos para que puedan participar en la sociedad que los acoge.

Pero, al mismo tiempo, estos grupos, conscientes de sus características y necesidades diferentes, buscarán defender sus derechos creando sus propios mecanismos los cuales, atendiendo a su sentido de comunidad, estarán definidos a partir de sus perspectivas, experiencias, filiaciones e intereses particulares. Es aquí donde podemos comenzar a 
observar la utilización de estrategias que tienen que ver con el empleo de elementos culturales o históricos que los definen.

El concepto de ciudadano que aquí se pretende rescatar es el de aquel individuo que no sólo es un receptor pasivo que goza de ciertos derechos, sino el de aquel que, como miembro de una comunidad, ha construido una identidad política a partir de la cual define su acción y participación política. Es el de aquel cuya participación se convierte en una competencia por la satisfacción y promoción de sus intereses; y cuya participación se realiza dentro de un campo político en el cual se mueve respetando las reglas definidas por este. Dichas reglas determinarán su acción y el tipo de relaciones sociales que entable con las distintas posiciones a las que se enfrente.

En este sentido, para el estudio de la construcción de los espacios políticos se utilizará la propuesta de Chantal Mouffe. Se considera que esta es la adecuada ya que, al diferenciar "lo político" de "la política" nos ofrece una buena herramienta de análisis. Reconociendo esta diferencia se podrán abarcar dos ámbitos importantes en la participación y construcción de espacios políticos. Centrándonos en el estudio de "lo político", visto como la esfera donde se manifiestan los antagonismos producto de las diversas identidades colectivas que ahí se construyen, se podrá estudiar la forma en que entablan sus relaciones las organizaciones indígenas e instituciones de gobierno. Por medio del estudio de los antagonismos y de los conflictos que estos generan se podrán dilucidar: a) los elementos identitarios que están en juego entre ambas partes; b) la forma en que dichos antagonismos van construyendo y definiendo las identidades y comportamientos grupales; y c) cómo se negocian y regulan intereses distintos definidos a partir de una identidad de grupo. Esta identidad estará basada en un proyecto común basado en el establecimiento de las fuerzas a las que hay que enfrentarse, en otros términos, "la otredad".

El campo político nos permite conocer cómo se están estructurando las relaciones con la “otredad" dentro de los espacios políticos, así como los conflictos, antagonismos, relaciones de poder, formas de subordinación y de represión que surgen y se manifiestan cuando existe una relación donde se están enfrentando intereses diversos. 
Por otra parte, el estudio de "la política" nos permitirá observar el marco a través del cual se enfrentarán las distintas posiciones. Esta representa el campo donde se negocian los intereses de grupo siguiendo las reglas de acción que ésta impone. Así "la política" consistirá en el intento continuo de hacer posible la coexistencia de las distintas posiciones, en un contexto de diversidad, de aspiraciones variadas y de intereses en conflicto. Considerando que en una sociedad democrática ya no puede existir un acuerdo final sobre un conjunto único de principios e ideas compartidas, se debe empezar a reconocer que la vida política está cargada de divisiones, de fuerzas opuestas y de definiciones en competencia. (Mouffe, 1999)

El estudio de estas divisiones y fuerzas opuestas nos lleva a retomar el análisis de la acción colectiva ya que esta implica la construcción de un "nosotros" en un contexto de diversidad y de conflicto (Mouffe, 1999). Tomando en consideración que la acción colectiva está definida por la creación de una identidad, entendida ésta como la construcción de un "nosotros" frente a un "ellos", será ésta la que movilice la participación en función de los intereses y definiciones del bien común construidos a partir de una comunidad. Las expectativas y formas de acción estarán determinadas por la identidad colectiva, a su vez, la identidad colectiva reflejara la complejidad interna del actor (sus orientaciones) y sus relaciones con el ambiente (otros actores, las oportunidades y restricciones). A través de estos, los actores valorarán el ambiente y calcularán los beneficios y costos de su acción (Melucci, 1999: 66).

Esto nos lleva a reconocer que la esfera política estará cargada constantemente de fuerzas antagónicas que buscarán defender o abrir espacios. Por lo que, la "acción colectiva" será "resultado de intenciones, recursos y límites, con una orientación construida por medio de relaciones sociales dentro de un sistema de oportunidades y restricciones" (Melucci, 1999). Esto nos ayudará a dilucidar la forma en que los actores definen sus propósitos y su actuar dependiendo de los límites y posibilidades que el mismo entorno político pueda imponerles; así como la forma en que, a través de las interacciones y las negociaciones, los actores se definen a sí mismos y a su campo de acción. 
Según Melucci, la construcción de un "nosotros" colectivo se define a partir de tres orientaciones: a) las relacionadas con los fines de la acción (el sentido que tiene para el actor la acción); b) las vinculadas con los medios (posibilidades y límites) y c) las que refieren a las relaciones con el ambiente (relaciones con los actores y disponibilidad de recursos) (Melucci, 1999)

Por lo que la acción colectiva no debe ser entendida sólo como una expresión de valores y creencias grupales, sino que ésta será resultado de la interacción, negociación y orientación de los individuos involucrados, éstos serán las que permitirán definir las posibilidades y límites de la acción colectiva. La definición de las posibilidades y límites serán las que determinen el tipo de relaciones que se entablen. (Melucci, 1999)

Es por esto que este proyecto propone el estudio de las relaciones que entablan dos actores dentro de un mismo campo político, esto nos permitirá conocer la forma en que cada uno irá definiendo su actuar dependiendo de sus posibilidades y límites que le impongan los grupos a los que se enfrenta y el mismo ambiente. Será a partir del estudio de la ciudadanía y de las relaciones sociales que ésta provoca como se podrá observar todos aquellos elementos involucrados en la forma en la que los grupos indígenas están construyendo sus espacios de participación política.

\section{Cultura}

\subsection{Problemáticas de la cultura en la antropología}

Para la antropología social la utilización del concepto de cultura ha resultado ser una guía y una herramienta muy eficaz para explicar las diferencias entre los pueblos. Este concepto ha sido un medio para comprender cómo el hombre logra adaptarse a su entorno social y ecológico e, incluso, cómo logra manipularlo en función de sus necesidades y proyectos. Las distintas formas en que cada grupo se adapta y responde a dichas necesidades y proyectos están determinadas por la cultura.

El problema surge cuando nos preguntamos cuál es el proceso por medio del cual la cultura adquiere contenidos diversos dependiendo de la sociedad que se trate. En la historia de la 
antropología, y en general todas aquellas disciplinas dedicadas al estudio del individuo en sociedad, esta pregunta ha tenido respuestas múltiples dependiendo siempre del contexto social que pretende explicar y de las escuelas o corrientes de análisis científico predominantes en el momento. Como sostiene Denys Cuche:

Las ciencias sociales, a pesar de su interés por la autonomía epistemológica, no son nunca totalmente independientes de los contextos intelectuales y lingüísticos en los que elabora sus esquemas teóricos y conceptuales. (Cuche, 1996: 8)

En este sentido podemos observar que en la reflexión científica, empezando por la filosofía hasta llegar al desarrollo de las ciencias sociales, ha existido un traslape relacionado con el hecho de que dicha reflexión ha estado influenciada por el contexto social bajo el cual se desarrolla y que puede llegar a determinar el tipo de análisis que se haga sobre la sociedad, es decir; en algunos casos han servido para explicar la realidad que se vive y, al mismo tiempo, para alimentar determinados intereses. Por lo que ha quedado pendiente la pregunta, que podría ser considerada de ética antropológica, ¿real y objetivamente estamos dando explicación a los fenómenos sociales que se nos presentan o simplemente estamos adaptado ciertas categorías analíticas atendiendo a determinados intereses?

Desde sus inicios la antropología ha enfrentado múltiples críticas provenientes de la relación entre sus marcos conceptuales y la realidad "que pretende" explicar. Estas críticas se desarrollaron desde el interior de la misma antropología. Ejemplo de esto son las críticas radicales hechas por representantes de la antropología postmoderna, éstos pusieron de relieve la ligazón entre antropólogos y colonialismo, rápidamente las críticas se trasladaron a cuestiones más profundas sobre la naturaleza de los marcos teóricos y, especialmente, sobre el grado en el que materializaban y portaban las premisas de la cultura occidental moderna:

El Etnógrafo solitario describió a los colonizados como miembros de una cultura armoniosa, homogénea internamente e inalterable. Ante tal descripción, esta cultura parecía "necesitar" al progreso, o una elevación económica y moral. (Rosaldo, 1991: 39) 
Estas críticas intentaron poner de relieve la forma en que los trabajos realizados bajo este contexto estuvieron dirigidas a mostrar las distintas culturas como un todo homogéneo y coherente producto de la estructura, los códigos y las normas sociales que regulaban el comportamiento social. Estas concepciones estuvieron encaminadas a justificar la dominación imperialista. ${ }^{9}$

Pero, al mismo tiempo, las propuestas de investigación de los partidarios de esta crítica también se pueden considerar como respuesta a un contexto de turbulencia política (19601970). En este contexto los investigadores buscaron analizar el proceso de descolonización y la intensificación del imperialismo que generó distintos movimientos en la lucha por los derechos civiles. En este sentido, los trabajos se enfocaron en la explicación de las nuevas formas de opresión basadas en el género, la preferencia o la raza. Esta etapa de reacomodo de la antropología buscaba generar nuevas teorías debido a que, en un contexto de homofobia y racismo, la noción de cultura, vista como algo homogéneo e integrado, ya no daba cuenta de las demandas de los grupos marginados y subordinados. En este contexto se pone en tela de juicio la propia noción de cultura. Tal como lo resume Rosaldo: "la noción recibida de cultura, como algo homogéneo e inmutable, no sólo era errónea, sino también irrelevante (por usar una palabra clave de la época)" (Rosaldo, 1991:43).

Los anteriores ejemplos nos muestran que la crítica a la antropología ha estado dirigida al hecho de que los conceptos y teorías que han guiado las distintas investigaciones han sido resultado de un etnocentrismo que pretende explicar las diferentes culturas a partir de nuestras propias nociones o de compromisos sociales definidos por el contexto social. Observamos cómo los marcos teóricos son elaborados para responder a ciertos interrogantes y a ciertos problemas que se plantean en periodos determinados y en contextos sociales y políticos específicos (Cuche, 1996:11).

\footnotetext{
${ }^{9}$ Emile Durkheim, aunque sociólogo, por sus propuestas de análisis ocupó una posición de fundador dentro de la antropología. Para Durkheim, las civilizaciones constituyen "sistema complejos y solidarios". Era el ámbito de lo social lo que determinaba la personalidad y la conciencia individual. Según su teoría, los elementos individuales están definidos por la "conciencia colectiva". "las formas colectivas de actuar o de pensar tienen una manera independiente de los individuos que, en todo momento, se adecuan a ella" (Durkheim, 1990). Era la conciencia colectiva la que unía y cohesionaba a la sociedad. En estas teorías el conflicto era considerado como algo patológico ya que el sistema se mantenía integrado y en armonía.
} 
Esta problemática inherente a la antropología ha provocado que la noción de cultura constantemente esté cargada de ambigüedades ya que el sentido que se le otorgue a su definición provendrá del contexto en el cual surja. Cada generación de científicos moderniza el lenguaje del debate, adaptándolo a la terminología científica en uso en cada momento: evolucionismo a finales del siglo XIX, organicismo a principios del siglo XX, la relatividad durante los años veinte. Sin embargo, aunque se expresen según nuevos códigos, los discursos sobre la cultura no son inventados libremente: hacen referencia a tradiciones intelectuales particulares que han persistido durante generaciones imponiendo concepciones de naturaleza humana y de la historia (Kuper, 2001:28).

\subsection{Cultura en movimiento}

Estos cambios en los marcos conceptuales en la antropología, además de reflejar que no han podido ser ajenos al contexto social en el cual se desarrollan, también nos muestran los esfuerzos por adaptar el análisis a las condiciones de un mundo cambiante, pone de manifiesto que el pensamiento antropológico está en constante reorientación y renovación.

La antropología se renueva porque cambian sus temas centrales y lo que se dice de ellos. ${ }^{\mathbf{1 0}}$ En la actualidad, la investigación antropológica requiere responder a los nuevos fenómenos provocados por la globalización como son: la multiculturalidad y los procesos que esta genera, así como el relacionado con el Estado-nación y la problemática que le impone la diversidad cultural en su interior. El fenómeno de la globalización y su contraparte, la diversidad cultural, traen implícitos el surgimiento de particularismos y el consecuente surgimiento de reclamos identitarios: sexuales, de género, étnicos, religiosos, así como la multiplicación de antagonismos basados en las diferencias.

En este ambiente los encuentros con las diferencias étnicas se han convertido en un fenómeno que invade la vida cotidiana moderna. Estos encuentros nos muestran que las fronteras culturales no están claramente delimitadas y están sujetas a un proceso continuo

\footnotetext{
10 "Las culturas ya no están aisladas de la nuestra. Occidente (o, tal vez, el capitalismo) había extendido sus tentáculos hasta la última hendidura del planeta. Y, sin embargo, los ciudadanos de los Estados pos coloniales no habían sucumbido llana y simplemente a la occidentalización. Los nativos estaban, y están, respondiendo. Rechazan las representaciones que hemos hecho de ellos, rehúsan continuar posando inmóviles para la cámara del etnógrafo y están enzarzados en sus propios proyectos culturales sincréticos" (Kuper, 2001: 243).
} 
de reelaboración, lo cual implica la negociación de referentes culturales cuya construcción depende tanto de lo que sucede al interior de cada grupo, como al exterior de estos.

En este sentido, el análisis de las fronteras culturales se vuelve central. Si consideramos, por un lado, que la diferencia "depende de la conservación de un límite" (Barth: 1976:17) y, por otro lado, que estamos en constante contacto con la diferencia; entonces, debemos tomar en cuenta que estos límites pueden cambiar y transformarse como consecuencia de la lucha al interior de cada grupo por conservar su especificidad o, según James Clifford, su autenticidad. Pero, al mismo tiempo, el estudio de las fronteras culturales debe tomar en consideración que cuando interactúan distintos grupos, también se requieren de determinados códigos o reglas de comunicación que les permitan interactuar. Para alcanzar a comprender e interpretar los significados que están inmersos en el establecimiento de las fronteras se requiere de un concepto de cultura ${ }^{11}$ que contemple la idea de que estamos:

"en un mundo donde las "fronteras abiertas" parecen más importantes que las "comunidades cerradas" (Rosaldo, 1991:51)

Presenciamos un mundo donde todas las culturas están frente a un proceso de hibridación que permite observar la capacidad creativa de los grupos, así como los conflictos que surgen cuando se lucha por mantener los lindes culturales. ${ }^{12}$ Estas nuevas circunstancia nos llevan a pensar que las concepciones tradicionales de cultura ${ }^{13}$ carecen de fundamento empírico porque habitamos un mundo caracterizado por la interdependencia y los constantes préstamos que atraviesan las fronteras nacionales y culturales. Por consiguiente, ya no hay culturas continuas, conservadoras y bien delimitadas, los individuos y grupos

${ }^{11}$ El concepto de cultura nos proporciona la única forma que conocemos de hablar sobre las diferencias existentes entre las gentes del mundo, diferencias que persisten, desafiando los procesos de homogeneización. (Kuper, 2001; Clifford, 1995)

${ }^{12}$ Siguiendo la propuesta de García Canclini, por hibridación se entienden aquellos "procesos socioculturales en los que estructuras y prácticas discretas, que existían en forma separada, se combinan para generar nuevas estructuras, objetos y prácticas". Esto reafirma la idea de que las construcciones culturales no son algo puro y estático, sino producto de la creatividad colectiva. (García, 1989:III)

${ }^{13}$ Por mucho tiempo el análisis antropológico definió a la cultura desde una dimensión normativa donde la cultura se determinaba por modelos, pautas, parámetros o esquemas de comportamiento. Los modelos culturales eran inculcados y sancionados socialmente. La actitud de los individuos con respecto a su propia cultura era pasiva y únicamente eran considerados como portadores de la cultura. Para una mejor revisión de los conceptos de cultura que guiaron a la antropología se puede ver Giménez, 1987. 
construyen sus sistemas de significado retomando elementos tanto de su pasado o historia local como de las nuevas circunstancias que enfrentan. ${ }^{14}$ Las culturas están en movimiento por medio de un constante proceso inventivo que las obliga a buscar nuevas maneras de modelar sus sistemas de significado. En este sentido coincidimos con la propuesta de James Clifford:

“La cultura es impugnable, temporal y emergente". (Clifford, 1995)

En un contexto donde las fronteras entre los países y entre las grandes ciudades no están claramente marcadas, es difícil hablar de culturas como unidades estables y con límites precisos. La intensifican de las interacciones disminuyen las fronteras entre los grupos como consecuencia de la mezcla constante de hábitos, creencias y formas de pensamiento distintos. Estas mezclas interculturales modifican y definen los contenidos de la cultura ${ }^{15}$ mediante dos tipos de procesos. Uno que se puede considerar de fusión y de cohesión donde cada grupo se apropia de determinados repertorios culturales, tanto de los provenientes de su pasado como de los que encuentra disponibles en sus interacciones; que le servirán para situarse en los nuevos contextos que enfrenta. Otro de confrontación. Tomando en cuenta que las mezclas culturales no pueden ser examinadas como algo homogéneo porque están caracterizadas por la desigualdad de poder, prestigio y recursos materiales (García Canclini, 1990); se considera que el tipo de apropiación que realizan los grupos depende de la confrontación y la negociación que se da en la lucha por acceder a determinados repertorios que les permitan entablar sus diferencias y marcar sus fronteras culturales. ${ }^{16}$ Es a partir de la forma en que se van integrando, fusionando y negociando los distintos repertorios culturales como se definirán las posiciones de los sujetos respecto de las relaciones interculturales.

Consideramos que las circunstancias sociales marcadas por un ambiente cambiante producto de la convergencia cultural, no pueden ser explicadas a través de aquellas

\footnotetext{
${ }^{14}$ Según James Clifford: "las raíces de la tradición se cortan y se reanudan y los símbolos colectivos se enajenan a partir de influencias externas". (Clifford, 1995:30)

${ }^{15}$ Sobre los procesos que encierra y la definición de cultura ver más adelante el apartado 2.3

${ }^{16}$ En el contexto de la investigación que se pretende realizar aquí, De la Peña, igualmente sugiere que todo el esfuerzo de los grupos minoritarios se orienta, no tanto a reapropiarse una identidad, sino a poseer los medios para definirla por sí mismos y según sus propios criterios (De la Peña, 1999).
} 
nociones sobre cultura que enfatizaban sobre entidades armónicas y equilibradas. Las diferencias culturales traen consigo antagonismos que requieren ser explicados a través de la cultura y las distintas identidades que se enfrentan. En este sentido, es importante conocer cómo la cultura y la identidad son la fuerza impulsora de estos antagonismos ocasionados por los continuos reacomodos que sufren las fronteras culturales.

\subsection{Cultura y relaciones sociales}

En un contexto donde los contactos culturales se vuelven algo cotidiano, existe el temor de la gradual pérdida de la autenticidad cultural, ${ }^{17}$ lo local al desvanecerse en lo global da paso a la pérdida de los productos puros y las tradiciones auténticas. Pero no se debe dejar de lado que la autenticidad es el sinónimo de la diferencia, es ésta la que selecciona los parámetros que definirán la esencia de una cultura y, si hablamos de diferencias culturales, no debemos olvidar que éstas siempre se construirán en oposición, según James Clifford:

Los reclamos de pureza son subvertidos siempre en todo caso por la necesidad de representar la autenticidad en oposición a alternativas externas, a menudo dominantes. (Clifford, 1988:27)

De esto se deduce que "la autenticidad es relacional" (yo frente al otro), por lo tanto, para que exista la autenticidad, debe existir una relación con la "otredad". En un ambiente caracterizado por las constantes relaciones interétnicas, encontramos que son estas las que están definiendo los elementos esenciales, limites y estrategias de comunicación entre grupos. Son estas relaciones, al definir el "nosotros" y los "otros", las que construyen distintos sistemas de significado. La cultura se va definiendo a partir dichas relaciones. A través de las relaciones entabladas entre grupos se crea un sistema de significado que da sentido a las acciones de los individuos. Según Barth:

Las distinciones étnicas no dependen de una ausencia de interacción y aceptación sociales; por el contrario, generalmente son el fundamento mismo sobre el cual están construidos los

\footnotetext{
17 Existen varias tendencias a afirmar que en un contexto de globalización las diferencias culturales se desvanecen producto de los efectos destructivos y homogeneizadores de la centralización económica y cultural. Estas tendencias postulaban que, con la configuración de un sistema mundial que propagaba una ideología unificadora basada en la critica hacía los valores de la tradición en las que se sustentaban los sistemas culturales y que enarbolaba la primacía del individuo frente a la comunidad; se esfumaría la diversidad cultural (Díaz-Polanco, 2000; Wallerstein, 1996).
} 
sistemas sociales que las contienen (...) las diferencias culturales pueden persistir a pesar del contacto interétnico y de la interdependencia (Barth, 1976:10)

En el contexto que analizamos las diferencias culturales no sólo persisten ante el contacto sino, que éste mismo las constituye y les otorga significados y contenidos diversos. Es en este cúmulo de relaciones donde tiene lugar la "reinvención de la diferencia" (Clifford, 1995). Se le puede llamar reinvención porque en el proceso de su constitución los rasgos que serán tomados en cuenta "no son la suma de las diferencias "objetivas" sino, sólo aquellas que los actores mismos consideran significativas" (Barth, 1976:15). Estos significados o categorías de identificación utilizadas por los actores estarán determinados por los propósitos que persigan y por el tipo de negociaciones y enfrentamientos que se presenten y tendrán la función de organizar las interacciones grupales.

$\mathrm{Si}$, como vimos con anterioridad, la autenticidad o diferencia está determinada por las relaciones de oposición; entonces, no puede haber esencia real, la autenticidad se vuelve una invención política, cultural o táctica que los ayuda a definirse y a entablar sus relaciones con los demás. En un espacio caracterizado por los constantes contactos culturales, si se hace un estudio de un grupo determinado podremos observar que este establece contactos con diferentes culturas y, si la cultura se constituye a través de las relaciones entre grupos, podemos ver que la cultura también es coyuntural, no esencial, su "esencia" se define en términos de la situación que enfrenta. (Clifford, 1995)

Las fronteras étnicas, al establecer la dicotomía entre un "nosotros" y los "otros", dan sentido y guían la vida social por medio de los valores y comportamientos que instituyen (Barth: 1976). Estas constituyen un referente para entablar las relaciones sociales. Al mismo tiempo, dichas fronteras se encuentran en constante reelaboración como resultado de las relaciones sociales que se entablan entre grupos. De esta manera, podemos concluir que la cultura es resultado de las relaciones sociales que se entablan entre grupos pertenecientes a una misma sociedad. Consideramos que el tipo de conflictos y negociaciones que se desarrollan en el transcurso de dichas relaciones son la base a partir de la cual se elaborarán y construirán los significados sociales que dan sentido a las acciones de los individuos. 
La cultura surgirá de la manera en que los grupos se organicen para entablar sus relaciones sociales. A partir de estas relaciones, los grupos construirán esquemas de significado que darán sentido a su vida cotidiana; guiará su actuar y además a partir de ella reelaborarán sus identidades y los rasgos que la definan. Este esquema será generado por los propósitos que se persigan y por el tipo de negociaciones y enfrentamientos que se presenten.

Siguiendo la idea de Cardoso de Oliveira y de Barth, la cultura se genera a partir de la forma en que los grupos étnicos organizan sus relaciones sociales. Por lo tanto, y en contraposición a los que apelan al contenido normativo de la cultura, la cultura no es la que define al grupo étnico, es éste el que se organiza para interactuar a partir de la creación de un conjunto de representaciones. Éstas son producto de un sistema de relaciones sociales que define los límites y posibilidades a través de los cuales actúan los individuos (Cardoso de Oliveira, 1992; Barth, 1976).

En este sentido, las representaciones sociales son resultado de la pugna social por designar y delimitar los sentidos por los cuales dichas relaciones se perciben. En esta pugna social los actores elaboran y reelaboran un cúmulo de significados sociales destinados a sustentar determinados contenidos o rasgos culturales que les ayuden a posicionarse en sus interacciones. Esta también nos ayuda a comprender y sustentar que la cultura no es estática ni normativa del comportamiento ni un todo coherente; ésta conlleva distintos procesos de resignificación que la hacen transformarse de acuerdo a las circunstancias. La atribución de significados se dará en torno a los conflictos, enfrentamientos y negociaciones que se generen dependiendo de los objetivos de los actores sociales y de los contextos históricos y socialmente específicos.

Será a través del estudio de la cultura, constituida por el tipo de relaciones sociales que se entablen, como se abordarán las formas de participación en las organizaciones indígenas y si tratará de conocer si existen los elementos suficientes para que pueda existir realmente la 
posibilidad de ejercer "una ciudadanía deseable". ${ }^{18}$ Este estudio se realiza considerando que la cultura se puede observar desde dos ángulos:

a) Objetivada. Este proceso se expresa en discursos y se muestra en acciones dirigidas a incidir en el tipo de relaciones que se entablan ya que, a partir de la exaltación de esos elementos diferenciadores, también se construye una imagen de sí mismos y ante los demás. Héctor Tejera define la objetivación de la cultura de la siguiente manera:

El proceso mediante el cual un individuo o grupo social construye un discurso que enfatiza, exagera o inventa ciertos aspectos de su identidad, vida cotidiana, entorno social, convicciones y creencias, interpretaciones sobre la historia nacional, entre otros, con el propósito de influir en la esfera política. Debido a que responde a situaciones coyunturales, la objetivación constantemente se renueva, y puede modificar las percepciones sociales sobre la sociedad, la política y el gobierno. (Tejera, 1999:18)

b) Subjetivada: en forma de habitus, entendido éste, como el sistema subjetivo de estructuras interiorizadas que construye los esquemas de percepción, concepción y de acción, según Bourdieu, el habitus se define como: ${ }^{19}$

\footnotetext{
Sistema de disposiciones adquiridas por aprendizaje implícito o explicito que funciona como un sistema de esquemas [schémes] generativos, es generador de estrategias que pueden ser objetivamente conformes con los intereses objetivos de sus autores sin haber sido expresamente concebidas con este fin (Bourdieu, 2000).
}

\footnotetext{
${ }^{18}$ Ciudadanía deseable en el sentido que plantea Kymlicka y Wayne (1997) y que se describe en las páginas 5 y 6 de este capítulo.

${ }^{19}$ Esta ángulo de la cultura será analizado más adelante.
} 


\section{Identidad étnica}

\subsection{Identidad y cultura}

En su sentido más general, la cultura es simplemente una manera de hablar sobre las identidades culturales. (Kuper, 2001:21) Al igual que la cultura, la identidad se ha convertido en un tema muy recurrente no sólo en el campo de las ciencias sociales, se habla de identidades políticas, fronterizas, de género, etc. Las condiciones que favorecieron o provocaron la diseminación creciente del término se ubican, en los años sesenta, bajo un contexto social en el cual se exacerbó la exaltación de la diferencia provocada por ideologías que exigían el reconocimiento de una sociedad multicultural.

La identidad surge como una herramienta que busca afrontar los problemas de integración de inmigrantes. Este contexto provocó un uso indiscriminado del término, lo cual, nos obliga a tener cuidado con las diversas definiciones de las que es objeto. Principalmente, con las que tienden a presentarla invariablemente como una entidad homogénea y sustancial con propiedades y atributos que se mantienen constantes y sin variaciones a través del tiempo. No debemos dejar de considerar que en una sociedad multicultural las fronteras étnicas están transformándose como producto de las relaciones interétnicas y de la necesidad de conservar las características distintivas de cada grupo. En este contexto la definición más apropiada debe considerar lo siguiente:

Es un proceso inventivo discontinuo, a menudo híbrido (...) uno es siempre inauténtico: atrapado entre culturas implicado en otras (...) no se puede ubicar un sentido de diferencia en la continuidad de una cultura o una tradición, La identidad es coyuntural, no esencial. (Clifford: 1995:25-26)

La identidad liberada de connotaciones esencialistas, y considerada como producto de las relaciones interétnicas que impone el contexto social, nos ayuda a entender la relación entre identidad y cultura. La primera es una construcción interiorizada, selectiva y distintiva que realizan los actores sociales. Pero no se debe olvidar que dicha construcción se realiza en el interior de marcos sociales que determinan tanto la posición de dichos actores, como la forma en que orientan sus representaciones y prácticas sociales. Estos marcos sociales son resultado de las relaciones sociales bajo las cuales toma forma la cultura. Por lo tanto, la 
identidad es resultado de un proceso de identificación en el seno de una situación relacional (Giménez, 2000).

\subsection{Identidad y etnia}

En nuestros días es muy común la asociación entre las nociones de etnia y cultura. En muchas ocasiones son consideradas homologas o son relacionadas entre sí como equivalentes, sin que en realidad se haya hecho una diferenciación clara entre una y otra. A partir de la revisión que hace Cardoso de Oliveira (1992) de los estudios basados en el análisis del concepto de cultura, desde el estudio de Kroeber y Kluckhohn, donde se hace una revisión de 161 conceptos sobre cultura; se puede observar una ausencia total de una referencia a la etnia.

La etnia se vuelve campo de interés antropológico en el momento en que se deja de lado las sociedades aisladas y, atendiendo a las problemáticas que imponía el nuevo contexto social, los estudios comienzan a inclinar por el análisis de las sociedades complejas en cuyo interior convergen diversos grupos étnicos. ${ }^{20}$ La noción de etnia entra en el terreno de las investigaciones en el momento en que surge la necesidad de explicar la incorporación de estos grupos minoritarios en sociedades más amplias. ${ }^{21}$ Igualmente, es en este momento donde la cultura y la etnia son consideradas parte de un mismo fenómeno enfocado hacia la búsqueda de todos aquellos elementos capaces de establecer diferencias entre los distintos grupos y a través de los cuales se construyera su identidad.

La antropología, al concentrarse en el estudio del contacto entre diversos grupos étnicos, encuentra que las poblaciones nacionales se transforman en etnias sólo cuando interactúan con grupos minoritarios que, para marcar su autenticidad, buscan determinadas orientaciones y características sociales contrastantes por medio de símbolos étnicos. En este

\footnotetext{
${ }^{20}$ Esto se constata considerando que la revisión del concepto de etnia se ha llevado a cabo bajo perspectivas constructivistas; en relación con conceptos como los de nación y ciudadanía y, con la preocupación de su adecuación empírica para abarcar los fenómeno étnicos que se manifiestan en el mundo entero, y no sólo en un país o una región particular. (Giménez, 2000)

${ }^{21}$ Las etnias no pueden disociarse del conjunto de la sociedad, éstas también están sometidas a los procesos de relación asimétricos existentes en el conjunto que las engloba. En este sentido, la etnia, considerada como una colectividad cultural disociada de su territorio (Giménez, 2000), está sometida a una situación marginal y de discriminación.
} 
sentido, lo étnico traspasa al grupo y se expresa "adjetivándolo", definiéndolo y atribuyéndole determinadas características impregnadas de un nosotros. La etnia se convirtió en un código capaz de orientar a los agentes en la situación interétnica (Cardoso de Oliveira, 1992)

En un contexto marcado por la constante búsqueda de elementos que unieran y diferenciaran, la etnia era percibida de distinta naturaleza: "las etnias son los otros, es decir los que se desvían de una manera u otra de la referencia identitaria americana" (Cuché, 1996:88-89). Esta distinción es consecuencia de su necesidad por conservar sus fronteras culturales. La conservación de estos límites depende de los códigos y normas de interacción que les son proporcionados a través de su organización social, ${ }^{22}$ por lo que, la organización social de la etnia era caracterizada como una cultura. Pero, al igual que en el caso de la relación identidad-cultura, lo que define a la etnia es el carácter de sus relaciones sociales, las diferencias que intenta remarcar son producto de los códigos y normas que rigen sus interacciones. A partir de sus relaciones sociales, la etnia construye parámetros de autoadscripción y adscripción que la distinguen y mantienen sus fronteras culturales. La etnia se construye a partir de la cultura, es decir, de las relaciones sociales que surgen en sus interacciones.

\subsection{Identidad social e identidad étnica}

La identidad social es un proceso de construcción simbólica de identificacióndiferenciación que se realiza sobre un marco de referencia: territorio, clase, etnia, cultura, sexo, edad. La identificación de los individuos se realiza por medio de categorizaciones sociales $^{23}$ utilizadas para definirse a sí mismos o a otras personas. La suma de estas categorías sociales es lo que se llama identidad social. Los grupos se consideran como tales en el momento en que un número determinado de individuos percibe una identificación común y se reconocen como portadores de las mismas categorías sociales, este

\footnotetext{
${ }^{22}$ Esto es entendido desde la perspectiva de Barth (1976), los grupos étnicos pueden ser entendidos como tipos de organización social, como sistemas organizativos, cuyos rasgos fundamentales serían los mecanismos de autoadscripción y adscripción.

${ }^{23}$ Los individuos categorizar con la finalidad de entender el orden social.
} 
reconocimiento debe de extenderse y ser validado por los actores con los que entra en contacto. La identidad de grupo es producto de dos procesos:

- Definición colectiva interna: resultado de la identificación de similitudes y diferencias que llevan a cabo los actores a través de relaciones que crean con otros actores significativos. Los propios actores que forman el grupo se vuelven conscientes de las características en común que poseen y los define como miembros.

- Definición colectiva externa: proceso de identificación exterior que se hace de los que no pertenecen al grupo; ésta se da mediante un proceso de categorización social que consiste en la identificación (por parte del actor externo) de determinadas características en común que comparten los actores que forman ese grupo.

El estudio de la construcción de la identidad social no sólo abarca la conformación de los parámetros de identificación que influyen en el comportamiento de los actores sociales. Este también debe involucrar otro aspecto que igualmente determina los contenidos de la identidad social. Estos aspectos tienen que ver con los procesos de construcción de sentido. La identidad también es un proceso de construcción de sentido a través de la selección de un determinado conjunto de atributos culturales. El sentido se convierte en un referente simbólico a partir del cual el actor social define los objetivos de su acción. Los grupos sociales procesan sus atributos culturales y los ordenan en su sentido, según las determinaciones sociales y los proyectos culturales implantados en su estructura social y en su marco espacial/temporal (Castells, 1997:28). ${ }^{24}$

Las formas de identidad social pueden ser muy variadas puesto que los diversos grupos sociales pueden desarrollar formas distintas de identidad al enfatizar dimensiones de diverso orden, éstos pueden constituirse básicamente a partir de condiciones económicas

${ }^{24}$ Siguiendo esta idea se puede decir que la creación de sentido también se da al interior de un campo, al estilo de Bourdieu, donde los significados que se les otorgan a las acciones están definidos por las reglas internas o habitus que imponen las determinaciones y proyectos a cumplir. 
comunes, de proyectos políticos compartidos y, también, a partir de componentes étnicos que articulan y estructuran concretamente elementos de orden sociocultural como: formas específicas de interrelación, ciertas características culturales, sistemas de organización social, costumbres y normas comunes, pautas de conducta, lengua, tradición histórica, etc. (Díaz-Polanco, 1988)

La identidad étnica es una especificación de la identidad social y consiste en la autoperpetuación subjetiva que tienen de sí mismos los actores llamados grupos étnicos. Un grupo étnico es una unidad social diferenciada, constituido como "grupo involuntario" (Giménez, 2000) que se caracteriza por formas tradicionales y no emergentes de solidaridad social, y que interactúa en situación de minoría dentro de sociedades más amplias. Así, pues, un grupo étnico es un conjunto social que ha desarrollado una fuerte solidaridad o identidad social a partir de los componentes étnicos. (Díaz-Polanco, 1988)

La noción de grupo étnico tiene una base estrictamente social. De acuerdo con la definición que hace Barth (1976), todo grupo étnico se encuentra constituido por una comunidad ${ }^{25}$ que $^{2}$ construye su identidad colectiva a lo largo de un proceso que involucra los siguientes elementos:

- La autoperpetuación biológica

- El compartir valores culturales fundamentales

- Integrar una arena de comunicación e interacción

- Contar con miembros que se autoidentifican a la vez que son identificados por otros, constituyéndose como una categoría claramente distinguible de otras categorías del mismo orden.

Las identidades correspondientes a estos grupos son identidades orientadas al pasado manifiestan gran lealtad a la tradición basada en el pasado, incluyendo raza, religión, lengua y otras tradiciones culturales.

\footnotetext{
${ }^{25}$ El efecto de comunidad surge de compartir símbolos, de la participación en un discurso simbólico propio que construye y reafirma las fronteras entre los miembros y los no miembros.
} 
La construcción social de las identidades étnicas tiene que ver, por un lado, con la caracterización e identificación que los individuos hacen de sí mismos. Si partimos de los planteamientos hechos por Cardoso de Oliveira (1992) y Barth (1976) y consideramos que la cultura es producto de la organización social de los individuos, podemos decir que el sentido que cobren sus acciones dependerá de la forma en que seleccionen sus atributos culturales. La identidad tiene que ver con el proceso de construcción de sentido, el cual, se convierte en una directriz que guía a los individuos o grupos en su desplazamiento por el espacio social. $^{26}$

Por otro lado, la identidad étnica tiene que ver con la existencia de sistemas culturales que envuelven en su interior a dos o más segmentos sociales con estructuras y dinámicas propias resultado de la diversidad de sus identificaciones y donde, además, existen relaciones de poder (Castells, 1997). Surge de la convergencia de varios grupos culturales que se articulan y conforman un campo marcado por la divergencia, siguiendo a Cardoso de Oliveira, la identidad sólo se despliega con el contacto interétnico o con la "cultura del contacto". (Cardoso de Oliveira, 1992:55).

El tipo de relación que los grupos entablan es determinante en la forma que adquieren las identidades. Presupone un cúmulo de relaciones sociales, así como un código de categorías destinado a orientar el desarrollo de dichas relaciones. Este código implica la afirmación de un nosotros frente a los otros o, como Cardoso de Oliveira la llama, Identidad contrastante (Cardoso de Oliveira, 1992:37). Es la concientización de la existencia de grupos diferentes lo que moviliza y da contenido a la identidad. La concientización del contacto genera la construcción de un conjunto de representaciones ${ }^{27}$ dispuestas como un catálogo de características que ayudan a establecer diferencias y, por lo tanto, a clasificarse a sí mismos y a los otros. Por lo tanto, la identidad emerge y toma forma por el contacto entre grupos, dicha forma dependerá del tipo de relación que entable con la otredad. Será a partir del

\footnotetext{
${ }^{26} \mathrm{El}$ sentido o dirección que toman sus acciones tienen que ver con "la identificación simbólica que realiza un actor social del objetivo de su acción". (Castells, 1997:29)

${ }^{27}$ Las representaciones sociales constituyen sistemas de disposiciones duraderas de percepción, interpretación y acción. Se encuentran internalizadas y se integran como formas subjetivadas de la cultura bajo la forma de habitus. A través de la formación de habitus las condiciones de existencia de cada grupo van imponiendo inconscientemente un modo de clasificar y experimentar lo real. (Bourdieu, 1990:35)
} 
conjunto de representaciones colectivas que se haga uno del otro como la identidad tomará forma.

Pero estas representaciones colectivas no son algo estático como pretende presentarla la concepción esencialista que concibe a la identidad como un conjunto de estable de propiedades y atributos específicos que se mantienen constante y sin variación en el tiempo. A medida que se ha disuelto la ilusión de las culturas fijas y coherentes, también lo hizo la seguridad de que las identidades se fijaban con el nacimiento o enraizadas en un sistema de estatus establecido. Según Clifford (1988) la identidad se ha descentralizado y fracturado. Esta toma sentido no sólo a partir de los elementos dados o recibidos, sino también en un constante proceso de resignificación producto de la necesidad de representar la autenticidad frente a alternativas externas o dominantes; es decir, como una forma de resistencia frente al poder.

La identidad está en un constante proceso de resignificación producto del tipo de relaciones que se entablan. Este hecho lo podemos constatar en los procesos de revitalización étnica que se han deslizado de posiciones defensivas a posiciones más dinámicas y agresivas. Si en el pasado prevalecían las estrategias asimilacionistas y adaptacionistas, en el presente los movimientos nos muestran tendencias hacía la autonomía. El Estado, con su tendencia ha reconocer una única identidad cultural legítima para todos los ciudadanos dentro de un territorio, aplicó categorías reductivas a las minorías. Es frente a estas circunstancias como se puede entender las reivindicaciones identitarias por parte de las minorías pertenecientes a un territorio nacional. Estas luchas están dirigidas a la reapropiación de los medios para que las minorías puedan definirse a sí mismas según sus propios criterios de identidad.

Igualmente, Gilberto Giménez define la identidad como:

El conjunto de repertorios culturales interiorizados (representaciones, valores, símbolos, etc.) mediante los cuales los actores sociales (individuales o colectivos) demarcan simbólicamente sus fronteras y se distinguen de los demás actores en una situación determinada, todo ello en contextos históricamente específico y socialmente estructurados (Giménez, 2002:37) 
Esta definición destaca tres rasgos principales de la identidad:

- Requiere de la reelaboración subjetiva de los elementos culturales existentes. Esta reelaboración implica una selección por parte de los sujetos de los elementos culturales que les caracterizan.

- Se construye en una situación relacional entre actores sociales. Es una construcción social que se realiza en el interior de los marcos sociales.

- Es resultado de un compromiso o negociación entre la autoafirmación y la asignación identitaria propuesta por actores externos.

Esto nos obliga a estudiar la construcción de las identidades tomando en consideración que debemos conocer cómo se están articulando estos rasgos para constituir y dar sentido a las formas de identificación de los individuos.

\section{4 Etnización}

Cuando se estudian las relaciones interétnicas es importante considerar que existen dos visiones; la primera tiene que ver con el sentimiento de pertenencia y el sentido general de etnicidad que experimentan los miembros del grupo; la segunda, con las características que le son asignadas por los individuos ajenos a ellos. Es importante considerar que la etnicidad tiene sus fundamentos en los profundos vínculos primordiales de un grupo: lazos fundados en un territorio común, parentesco y vínculos de sangre, lenguaje, religión y costumbre. Pero al mismo tiempo se debe considerar que dichos vínculos también pueden ser utilizados como instrumentos políticos con el propósito de obtener beneficios para un grupo determinado. En este sentido el estudio de la etnicidad nos ayuda a entender cómo se constituyen las identidades en un marco social caracterizado por las constantes luchas culturales y políticas en las que se han encontrado inmersos los grupos étnicos.

Frederick Barth (1976) se oponía a la idea de que la etnicidad era un conjunto de rasgos particulares atribuidos únicamente a aquellos grupos que permanecían aislados y totalmente ajenos a las influencias del exterior. Por el contrario, sostenía que la etnicidad, considerada como la organización social de la diferencia cultural, constituía un fenómeno que se 
expresaba en las zonas sociales fronterizas en donde los intereses de los grupos se encontraban amenazados y en donde eran más débiles frente al exterior. En estas zonas resultaba de vital interés demarcar las fronteras a través de la demarcación de identidades étnicas. Por lo tanto, lo que realmente importa para explicar la etnicidad no es tanto el contenido cultural de la identidad considerado aisladamente, sino los mecanismos de interacción que, utilizando cierto repertorio cultural de manera estratégica y selectiva, mantienen y cuestionan las fronteras culturales.

En este sentido el fenómeno de la etnicidad encierra dos procesos: relaciones de poder y una estrategia para mantener las fronteras culturales. El primero, parte del hecho de que "un grupo étnico no existe por sí sólo en ninguna parte del mundo" (Stavenhagen, 2000:36) se debe tomar en cuenta el marco político y económico donde tienen lugar las relaciones entre los grupos étnicos. La etnicidad cobra sentido en aquellos contextos donde existe una comunidad mayor que encierra a otros grupos minoritarios. Generalmente se les asignan como minorías, término que no tiene una connotación numérica, sino que designa la no participación en las redes sociales. El grupo en cuestión en algunos casos podría ser mayor en términos numéricos. ${ }^{28}$

La noción de minoría, al no tener connotaciones numéricas, generalmente tiene que ver con el ejercicio de poder, ya que son los grupos que detentan el poder los que asignarán las características de estos grupos. En el proceso de etncización no sólo es importante la autoimagen sino también la imagen externa ya que el concepto que un grupo tiene de sí mismo también depende del hecho de que exista un grupo externo con respecto al cual el grupo se defina. En este sentido la etnicidad también se construye por las nociones que los grupos mayoritarios tienen de los llamados minoritarios.

El segundo, como una estrategia que intenta mantener las fronteras culturales. En la construcción de identidad los grupos establecen fronteras que ponen de relieve las

\footnotetext{
${ }^{28}$ La minoría no se definen sólo con respecto a la mayoría (entendida como lo que la sociedad considera normal), sino por las relaciones conflictivas que ambas mantienen. Cada sociedad define sus minorías, sus formas de vida, de integración o de exclusión. Por tal motivo, para entender a las minorías se requiere del estudio de poder (Giglia, 2000:432).
} 
diferencias entre el mundo propio y ajeno. Normalmente son los grupos sociales dominantes los que crean las fronteras que los distinguen de los grupos dominados. No obstante, en respuesta, los grupos dominados empiezan a construir sus propias fronteras, oponiéndose a las categorías con los que la clase dominante los ha estigmatizado. La construcción de identidad en los grupos dominados generalmente conduce a la tendencia de distanciarse de los valores y estructuras de significado de la cultura dominante, afirmando valores y estructuras alternativas.

En un contexto donde se ha desarrollado una relación asimétrica entre los grupos que conviven podemos observar cómo la sujeción del indio y la dominación del blanco permite la aparición de distintas ideologías étnicas. La etnicidad puede ser considerada como una ideología étnica porque orienta a las poblaciones indígenas en su lucha por sobrevivir al contacto con los segmentos no-indios de la sociedad nacional ante los cuales se encuentra en una situación de desigualdad. La conscientización de esta situación de desigualdad moviliza y da contenido a la identidad.

La construcción de la identidad, al suponer la confrontación con otros grupos o identidades, construye "una visión del mundo" que orienta a los individuos en las relaciones de competencia y conflicto que viven. Dichas relaciones generan una representación colectiva etnocéntrica que es engendrada por una concepción del otro no relativizada (Cardoso de Oliveira, 1992:75). La identidad, al partir de una confrontación entre nosotros y los otros, construye un conjunto de representaciones que no admiten una concepción igualitaria entre etnias; si la identidad no tuviera estos tintes ideológicos ésta supondría la igualdad entre todos los grupos, pero, como hemos visto, las categorías de adscripción y autoadscripción están cargadas de valor (puntos de vista de los propios agentes). La identidad étnica, como una ideología fuertemente "etnocéntrica", se convierte en marco de referencia, de modo tal que puede atravesar las relaciones sociales contenidas en el sistema interétnico y, en consecuencia, el comportamiento de los agentes en él insertados. 


\section{5 La identidad como estrategia}

Las fluctuaciones de la identidad étnica -gracias a su capacidad de variación, de reacomodamiento y de manipulación- y el ejercicio de la identificación, deben ser interpretados como un esfuerzo del individuo y del grupo para lograr sus objetivos. Tomando como referencia que las concepciones que se tienen sobre sí mismo y los otros son expresados en símbolos ${ }^{29}$ que hacen alusión a elementos significativos de la pertenencia a un grupo con características específicas, consideramos que estos símbolos serán seleccionados con la finalidad de obtener reconocimiento y legitimidad. ${ }^{30}$

Como hemos visto la identidad está en una constante búsqueda de criterios objetivos que la sustenten. Estos criterios tienen tres funciones:

1. Crear representaciones mentales que son actos de percepción y de apreciación en los que los actores invierten sus intereses y presupuestos ${ }^{31}$

2. Crear representaciones objetivas (emblemas o insignias)

3. Actos que consisten en la manipulación simbólica que persigue determinar la representación mental que los demás puedan formarse de dichas propiedades y sus portadores. (Giménez, 1987:475)

Estos criterios en la práctica se convierten en formas de ejercer poder por medio de signos o emblemas. Si, como hemos visto, la identidad se caracteriza por su naturaleza representacional y por la lucha simbólica por las clasificaciones, podemos observar que la identidad se convierte en una estrategia en el momento en que consideramos, por un lado, que las representaciones contribuyen a producir lo que describen: la realidad objetiva y, por otro lado, las clasificaciones tienen funciones prácticas y están orientadas hacia la

\footnotetext{
${ }^{29}$ Los sistemas simbólicos son utilizados como instrumento de ordenamiento de la conducta colectiva, esto es, en la medida en que son absorbidos y recreados en las prácticas sociales. Son al mismo tiempo representaciones ("modelos de") y orientaciones para la acción_("modelos para") (Giménez, 1987).

${ }^{30}$ La identidad para que exista socialmente requiere del reconocimiento de los demás actores, según Bourdieu "el mundo social es también representación y voluntad, y existir socialmente también quiere decir ser percibido, y por cierto ser percibido como distinto" (Bourdieu, 2000)

${ }^{31}$ A este proceso Melucci lo llama identidad colectiva y consiste en el hecho de que para que un actor pueda elaborar sus expectativas y evaluar sus posibilidades y límites se requiere de la capacidad de definirse a sí mismo y a su ambiente (Melucci, 1999:66).
} 
producción de efectos sociales. La identidad se convierte en un objeto de disputa en la lucha por obtener una clasificación legitima. En esta lucha no todos tienen el mismo poder de identificación.

La lucha por las representaciones que se da en la construcción de las identidades está destinada a manipular las imágenes mentales ya que organiza las manifestaciones adecuadas para modificar las representaciones. Por lo tanto, en la lucha por las clasificaciones existe también una relación de poder que intenta propagar una visión del mundo social imponiendo categorías de percepción. Estas categorías dan sentido a la realidad por medio de la objetivación del discurso o por la exaltación de los criterio objetivos. Los criterios objetivos son utilizados como armas (Giménez, 1987:477) debido a que apoyan en la designación de los rasgos que sustentan las representaciones mentales que tiene el grupo al interior como la que pretende construir al exterior.

Los grupos étnicos recurren a varios elementos con el fin de reivindicar sus identidades. Gilberto Giménez los enlista de la siguiente manera:

- La tradición archivada en la memoria colectiva. Por tradición ha de entenderse un conjunto de representaciones, imágenes, saberes teóricos y prácticos, comportamientos, actitudes que un grupo acepta en nombre de la continuidad necesaria entre el pasado y el presente. La base de la autoridad de la tradición descansa en el hecho de conferir al pasado una autoridad trascendente para regular el presente. ${ }^{32}$

- Los territorios ancestrales son lugares donde se enfatiza la memoria colectiva y constituyen un referente simbólico de la identidad social. El territorio es el soporte

\footnotetext{
${ }^{32}$ En este punto debemos considerar que, según Giddens, la construcción consciente de una tradición no ha existido desde tiempo inmemorial, ésta se da en la era moderna, por lo que, las tradiciones no son genuinas, sino artificiales y que, en lugar de crecer espontáneamente, son utilizadas para ejercer el poder. Cualquier continuidad que impliquen con el pasado remoto es esencialmente falsa. Todas las tradiciones son inventadas. Ninguna sociedad tradicional fue totalmente tradicional, y las tradiciones y costumbres han sido inventadas por varias razones. Estén o no construidas de manera deliberada, siempre llevan incorporadas poder, Reyes, emperadores, sacerdotes y otros las han inventado desde hace mucho tiempo en su beneficio y para legitimar su dominio. Por lo que es erróneo pensar que las tradiciones son impermeables al cambio, éstas se desarrollan en el tiempo, pero también pueden ser repentinamente alteradas o transformadas o, en otros términos, son inventadas y reinventadas (Giddens, 1999).
} 
material de la vida comunitaria, es la herencia común, la tierra de los padres y de los antepasados. Es el vínculo material entre las generaciones del pasado y del presente. $^{33}$

- El lenguaje o dialecto como símbolo distintivo de la identidad cultural y un código que comprendía la visión del mundo de una colectividad.

- El sistema de parentesco como fundamento de la pertenencia grupal. La pertenencia étnica se adquiere fundamentalmente por el nacimiento a través de la inserción dentro del sistema de parentesco.

- El complejo religioso que reafirma la identidad del grupo al dramatizar la visión del mundo, de la vida y de la muerte. Es una religión ritual que se gira en torno a la figura de los santos patronos y de las celebraciones festivas hechas para honrarlos

Los esfuerzos de los grupos étnicos estarán orientados ha seleccionar, ordenar y utilizar estos elementos con la intención de reapropiarse de los medios que les permitan definir por sí mismos, y según sus propios criterios, su identidad. Retomar el análisis de estos elementos nos servirá para detectar cuáles y por qué son seleccionados como símbolos de identidad étnica. Igualmente, nos servirá para conocer cuáles son las lógicas sociales que impulsan a los grupos a identificarse, categorizar y clasificar.

Pero, además del estudio de la construcción de la identidad étnica, no debemos pasar por alto que, siguiendo lo dicho anteriormente, en esta perspectiva la identidad aparece como un medio para alcanzar una finalidad ya que, les permite cierto margen de maniobra debido a que dependiendo del balance que hagan de las situaciones y de sus intereses podrán

\footnotetext{
${ }^{33}$ A pesar de que los grupos indígenas han transitado de su lugar de origen a otros centros urbanos, el territorio sigue un referente identitario. Guillermo de la Peña y Regina Martínez llaman "comunidades morales" a esas colectividades que se reproducen -en vez de disolverse y asimilarse- gracias a la resignificación de los modelos culturales vigentes en sus localidades de origen. Los grupos étnicos migrantes vuelven inteligible el mundo urbano al interpretarlo desde las categorías significativas con las cuales fueron socializados; pero estas categorías a su vez son negociadas y actualizadas al aplicarse a nuevas experiencias. (De la Peña y Martínez, 2002) Por su parte, Oehmichen igualmente sostiene una idea de comunidad que traspasa las fronteras territoriales. Sugiere que las fronteras étnicas no siempre se corresponden con las fronteras físicas. A través de redes que se extienden en el espacio nacional e internacional han tendido a reconstituir sus vínculos sociales, a recrear un tipo de comunidad multicéntrica y muchas veces binacional, y a dinamizar las relaciones sociales que unen a los migrantes con sus lugares natales o de origen. (Oehmichen, 2003)
} 
utilizar de manera estratégica sus recursos identitarios. Pero las estrategias que se utilicen también dependerán de la correlación de fuerzas entre los grupos o actores sociales en contacto. El término de estrategia identitaria no significa que los actores sociales sean completamente libres para definir su identidad según sus intereses materiales y simbólicos del momento. Las estrategias también deben tomar en cuenta el marco estructural, la situación social, la correlación de fuerza entre los grupos, las maniobras de los demás, etc.; es decir, las estrategias deben ser analizadas, según Bourdieu, a partir del estudio de la estructura de los campos:

La estructura del campo es un estado de la relación de fuerzas entre los agentes o las instituciones que intervienen en la lucha o, si ustedes prefieren, de la distribución del capital específico que ha sido acumulado durante luchas anteriores y que orientan las estrategias ulteriores (...) Hablar de capital específico significa que el capital vale en relación con un campo determinado (Bourdieu, 1990:136)

En este caso el capital específico o el fundamento de poder y de autoridad, es la lucha por la apropiación de la identidad. Si bien es cierto que la identidad es manipulable y se presta a la instrumentalización, también es cierto que los grupos no pueden hacer lo que quieran ni imponer su identidad ya que, como se ha mencionado, ésta será resultado de la identificación que nos atribuimos nosotros mismo y de la que nos atribuyen los demás. Esta tendrá que ser resultado de la lógica interna del campo, será a partir de sus propiedades y leyes generales de funcionamiento como se estructurará la lucha por la clasificación.

Otra propiedad menos visible de los campos es que son producto de los intereses comunes:

Toda la gente comprometida con un campo tiene una cantidad de intereses fundamentales comunes, es decir, todo aquello que está vinculado con la existencia misma del campo (Bourdieu, 1990:137)

Estos intereses comunes son los que inconscientemente impondrán las exigencias o reglas que orientarán las percepciones, orientaciones y acciones de los individuos involucrados en un campo. Estas reglas son llamadas habitus e implican el conocimiento y reconocimiento inconsciente de las reglas o leyes inmanentes al campo, y se consideran instrumentos de 
traducción ya que a través de ellos se construye un sentido común que no necesita de una concertación colectiva planeada, pero que sin embargo dispone y orienta las acciones.

En este sentido las estrategias que se utilizan pueden estar objetivamente conformes con los intereses de sus autores, pero sin haber sido concebidas expresamente con este fin. Pueden ser resultado de la estructura del campo, vista como el estado de la relación de fuerzas entre los agentes que intervienen en la lucha por la clasificación, la cual inconscientemente orienta el sentido de sus acciones. En la lucha que se da por legitimar las identidades, la utilización de determinados elementos culturales en las relaciones interétnicas pueden ser resultado de una percepción externa, es esta la que inconscientemente puede estar definiendo las acciones del grupo en cuestión y las estrategias utilizadas.

\section{Construcción de espacios políticos en organizaciones indígenas del DF}

\subsection{Contexto social de investigación}

La constante migración de población indígena a la ciudad de México ha sido consecuencia de la situación de pobreza que padecen en sus lugares de origen. Estas migraciones han transformado aspectos importantes de la forma de vida indígena. Al romperse los límites territoriales que definían su comunidad entraron en un proceso de reelaboración de sus vínculos y relaciones sociales, pero esta reelaboración ha estado enfrentada constantemente con el rechazo y menosprecio provenientes de los prejuicios y estereotipos que ha construido la cultura mexicana. Los altos índices de población indígena radicada en la ciudad de México y sus alrededores han puesto al descubierto un fenómeno que no podemos pasar por alto: la diversidad cultural. Esta diversidad cultural, frente a los discursos sobre una sociedad democrática, nos enfrentan a la necesidad de estudiar la forma en que están manifestando su presencia, concretamente en el ámbito político, se requiere conocer la forma en que los grupos indígenas están buscando los canales necesarios que les permitan participar políticamente y tener espacios de representación en un territorio donde son una minoría. 
Se requiere conocer el tipo de actividad política que realizan los grupos que se encuentran en una posición de desventaja, en cuanto al acceso por los recursos. Se estudian los grupos indígenas migrantes a la ciudad de México porque actualmente son un fenómeno social que no podemos pasar por alto. Existen estudios que han analizado este fenómeno migratorio tratando de encontrar las condiciones y formas de inserción (culturales, sociales y económicas) (Arizpe, 1975; 1985; Hiernaux-Nicolas, 2000, Valencia, 2000; Oehmichen, 2001). Dichos estudios demuestran que los indígenas han migrado a la ciudad movidos por necesidades similares tales como: el estilo de vida en la ciudad y niveles de ingreso. Según una encuesta realizada por Hiernaux-Nicolas en su investigación sobre indígenas en el Valle de Chalco, la necesidad y la pobreza representa un 39\% de las causas de migración; la necesidad de conseguir un trabajo el $20.6 \%$ y $14 \%$ por los deseos de mejorar sus ingresos; reunidos estos porcentajes, el 75\% de las causas de migración se refieren a cuestiones económicas y el $25 \%$ restante están relacionadas con cuestiones de salud o educativas (Hiernaux-Nicolas, 2000).

En general, las condiciones de vida de los indígenas migrantes que residen en el Distrito Federal y en la zona oriente han sido muy precarias; tienen dificultades para acceder a los derechos sociales básicos, como la salud pública, vivienda o un trabajo bien remunerado. Las actividades en las que encuentran empleo son básicamente las que menos conocimientos formales requieren como: la construcción, el comercio ambulante y el servicio doméstico, las cuales se caracterizan por los bajos salarios y la falta de seguridad y derechos laborales.

La heterogeneidad cultural característica de las zonas urbanas en México se hace presente a partir de los años cuarenta y cincuenta cuando, ante al alto índice de explotación y marginación que se vive en las áreas rurales, comienzan a concentrarse en la ciudad diversos grupos migrantes que venían en busca de mejores oportunidades de vida. Este éxodo masivo ha sido explicado de diversas formas. Existen las que se refieren al hecho de que México generó un intercambio económico desigual que provocó un desequilibrio entre sus regiones expulsando a los pobladores de aquellas menos favorecidas en dicho intercambio. En un periodo en el que se promovió la industria el ingreso agrícola descendió 
y las actividades artesanales, el pequeño comercio, los oficios, etc. disminuyeron provocando que la población rural se hiciera cada vez más dependiente del trabajo asalariado. $^{34}$

Otras explicaciones, con matices políticos, aducen la migración a la falta de políticas de Estado adecuadas. El Estado implementó políticas de desarrollo que, al centralizar los recursos y las inversiones en los centros urbanos, estimularon la industrialización y la urbanización a expensas de la agricultura. Otras hacen referencia al crecimiento acelerado de la población e indican que en la distribución de la tierra no se contempló el incremento natural de la población, por lo que llegó un momento en el que el tamaño de las parcelas no alcanzó para asegurar la subsistencia de las familias. Otras tienen que ver con la influencia que ejercen los medios masivos de comunicación por medio de la exaltación del medio urbano y su forma de vida. (Arizpe, 1985)

Las principales causas que determinan la migración se pueden enumera de la siguiente manera (Valencia, 2000):

- Escasez y baja calidad de tierra

- Pocos apoyos financieros y técnicos

- Escasez de oportunidades de empleo en las distintas actividades productivas

- Conflictos políticos, sociales y religiosos

- Precarias condiciones económicas y sociales

- Marcados índices de pobreza, pobreza extrema y marginalidad social

- Explosión demográfica

En la ciudad de México el crecimiento de la industria y la consecuente demanda de servicios que ésta provocó, impulsaron el empleo, por ejemplo, en los años cuarenta se

\footnotetext{
34 En general se sostiene que es a partir del régimen de Miguel Alemán cuando se acelera la migración, principalmente, hacía la Ciudad de México. Las políticas de Estado promovidas por dicho régimen impulsaron la industrialización. El apoyo del Estado a la agricultura capitalista, tendiente hacía la concentración de grandes extensiones, fue desplazando a los pequeños productores quienes se vieron obligados a emigrar hacía las zonas que les ofrecían mejores oportunidades.
} 
generaron 503000 empleos, 686000 en los cincuenta y 679000 en los sesentas (Arizpe, 1985). Este aumento significativo en la creación de empleos se convierte en el principal factor de atracción para una población que buscaba mejorar su condición económica. Para los indígenas, como para muchos otros, la migración fue una estrategia de supervivencia económica debido a la profundización de la crisis económica que han padecido sus regiones y comunidades, lo que llevó a muchos de ellos a tomar la decisión de abandonar sus comunidades para mejorar su condición de vida.

Pero en este desplazamiento de grupos que dieron vida a la ciudad, aunque en general el nuevo espacio ofrecía mayores oportunidades de desarrollo, no todos tuvieron las mismas oportunidades para insertarse de la mejor manera. Los mestizos de diversas entidades que migraron a la ciudad se enfrentaron con menos dificultades de integración, en comparación con los grupos indígenas. Los mestizos, conservaran o no rasgos de sus identidades regionales, tuvieron la ventaja de pertenecer a la misma cultura de las mayorías capitalinas, por lo que su integración fue menos conflictiva. Ejemplo de esto lo encontramos en las instituciones educativas las cuales les permitieron acceder a una educación en su lengua materna, el español, además de que dentro de ésta se valoraba la cultura a la que pertenecían. Este no fue el caso de los indígenas quienes constantemente se enfrentaron a situaciones difíciles como la complejidad lingüística, la ardua inserción laboral, marginalidad y discriminación que les obligaron a dejar de lado rasgos importantes de su cultura. ${ }^{35}$

Los índices censales nos muestran que una raíz importante de la diversidad cultural en el Distrito Federal es la migración indígena procedente de distintos pueblos y entidades del país. Según el Censo del 2000, el Distrito Federal comprende 5 grupos de lenguas indígenas: Náhuatl, Otomí, Mixteco, Zapoteco y Mazahua, que corresponden a las comunidades indígenas migrantes.

\footnotetext{
${ }^{35}$ En general se han insertado en condiciones de vida precarias y de extrema pobreza, no cuentan con empleo formal, tienen dificultades de acceso a la vivienda, a la educación, a la salud y a la justicia equitativa. (Valencia, 2000)
} 
Población de cinco años y más hablante de lengua indígena en el Distrito Federal

\begin{tabular}{|l|r|r|}
\hline Lengua & Total & Estructura \% \\
\hline $\begin{array}{l}\text { Población de 5 años y más que habla } \\
\text { lengua indígena }\end{array}$ & $\mathbf{1 4 1} \mathbf{7 1 0}$ & $\mathbf{1 0 0 . 0}$ \\
\hline Náhuatl & 37450 & 26.4 \\
\hline Otomí & 17083 & 12.1 \\
\hline Mixteco & 15968 & 11.3 \\
\hline Zapoteco & 14117 & 10.0 \\
\hline Mazahua & 9631 & 6.8 \\
\hline Las demás lenguas indígenas & 30313 & 21.4 \\
\hline No especificado & 17148 & 12.1 \\
\hline
\end{tabular}

(INEGI, 2000)

Como se vio con anterioridad, este tipo de migración se inicia a partir de los años cuarenta.

Desde entonces los indígenas se han ido asentando en diferentes delegaciones del Distrito Federal, principalmente en la de Iztapalapa, Gustavo A. Madero, Coyoacán, Álvaro Obregón, Tlalpan y Cuauhtemoc (INEGI, 2001). También existen importantes asentamientos de población indígena inmigrante que reside en municipios adyacentes al Distrito Federal, que corresponden al Estado de México. ${ }^{36}$ Para el caso de los municipios conurbados del Estado de México, los porcentajes más elevados de población indígena se verifican en Chimalhuacán, Chalco, Naucalpan, Nezahualcoyotl y Ecatepec (HiernauxNicola, 2000).

Investigaciones sobre el proceso migratorio han demostrado que se concentran en estas zonas debido a los bajos costos de vivienda y servicios, además de las redes de parentesco que existen y que los llevan ha habitar los mismos espacios. Estos estudios han demostrado que los indígenas migrantes que proceden de una región y estrato étnico común tienden a reunirse en los mismos barrios o colonias, lo que les permite mantener cierta cohesión y reproducir algunos elementos de su identidad (fiestas patronales, costumbres y creencias),

\footnotetext{
${ }^{36}$ Se sostiene que a partir de 1980 la Ciudad de México empieza a perder población, de hecho, primero se redujo su velocidad de crecimiento: en 1980 su tasa anual de crecimiento era de 3.2\%, entre 1990 y 1995 era de $1.9 \%$ y entre 1995 y 2000 fue de $1.5 \%$. Esta baja en el crecimiento es contrastada con el hecho de que, mientras el DF perdía población, los municipios del Estado de México, ubicados en la periferia del DF, han presenciado un crecimiento anual de 1.6\%. Lo cual sustenta la idea de que el DF se convirtió en expulsor de población hacía dichos municipios. (Iracheta, 2003).
} 
así como también apoyarse o protegerse de situaciones que derivan de su vulnerabilidad en la ciudad. (Arizpe, 1975; 1985; Hiernaux-Nicolas, 2000; Oehmichen, 2001) ${ }^{37}$

Un aspecto importante en la inserción del indígena a la ciudad es su relación con las instancias de gobierno responsables de impartir justicia. El sistema judicial se torna problemático cuando en casos judiciales están involucradas personas indígenas, ya sean culpables, inocentes o víctimas. La falta de recursos para pagar abogados defensores, la ausencia de traductores indígenas, las diferencias culturales (deficiente dominio de la lengua española y la denigración e intolerancia hacía sus culturas) y las normatividades que no atienden este tipo de casos son algunos de los múltiples problemas a los que se enfrentan los indígenas cuando acuden a las instituciones de gobierno. Las políticas gubernamentales, por lo general, han estado encaminadas a buscar que los indígenas asimilen a las reglas y pautas de la cultura mayoritaria y renuncien a sus culturas particulares, por lo que, en general, han carecido tanto de apoyos que les permita perpetuar y difundir su cultura, así como una política de gobierno que atienda sus demandas de participación y representatividad en los órganos donde se discuten y deciden los asuntos que les compiten.

Como una forma de reacción ante la exclusión de que han sido objeto a través de la historia, a partir de la década de los ochenta aumentan las demandas de organizaciones étnicas que solicitaban se ampliaran los espacios públicos para incluir las expresiones de la diferencia étnica. Estas expresiones han buscado ampliar el ámbito público e incluir las representaciones de las diferencias étnicas. En los últimos años han surgido ciertas organizaciones representantes de pueblos indígenas que se manifiestan e insisten en una integración basada en el reconocimiento de la diversidad cultural. Ejemplo de esto es el surgimiento de organizaciones de oposición como la Coordinadora Nacional Plan de Ayala con un liderazgo de intelectuales indígenas que pregonaban que la educación de los

\footnotetext{
${ }^{37}$ Otras de las causas por las que se han concentrado en zonas aledañas al DF aluden al hecho de que debido a la escasez de vivienda y la falta de servicios, provocados por los terremotos ocurridos en 1985, así como la falta de empleo; por políticas de descentralización públicas y privadas; problemas de contaminación, etc. mucha población tuvo que buscar otros asentamientos. En lo referente a las razones por las cuales eligen la zona oriente del DF es porque proporciona oportunidades de educación, espacios habitacionales a menor precio y toda una red de comunicaciones que les permite conectarse con el DF fácilmente (Valencia, 2000, Iracheta, 2003).
} 
indígenas debía comenzar por el conocimiento y aprecio de su propia cultura (Warman y Argueta, 1993; De la Peña, 1999).

La exigencia de la apertura de los espacios políticos en el caso de la ciudad de México se manifiesta, por un lado, en la presencia de organizaciones de indígenas encargadas de gestionar ante las autoridades capitalinas los reclamos sociales, económicos, culturales y políticos de sus miembros. Como portadoras de un conjunto característico de valores, costumbres y creencias, estas organizaciones están encaminadas a reivindicar el reconocimiento de la pluralidad cultural y la existencia de las comunidades indígenas migrantes en la ciudad, principalmente, insisten en la promoción de políticas públicas que apoyen e impulsen su desarrollo social y económico. Por otro lado, los aparatos del gobierno han reconocido a las organizaciones indígenas existentes en el DF y han respondido creando un consejo consultivo dedicado a la atención de las problemáticas indígenas en la ciudad.

\subsection{Actores sociales que involucra la investigación}

\section{a) El Consejo de Consulta y Participación Indígena del DF}

En la construcción de los espacios políticos de los grupos organizados como portadores y defensores de lo étnico, el tipo de respuesta que reciban de las autoridades es primordial; ya que será un punto de referencia importante a partir del cual defina su actuar y desempeño. En este sentido, nos centramos en el estudio del papel que desempeña el Consejo de Consulta y Participación Indígena del Distrito Federal. Nos enfocamos en dicho consejo porque ahí convergen representantes de gobierno, del ámbito académico y las organizaciones indígenas y, por lo tanto, es el lugar idóneo para apreciar el tipo de relación que se entablan estos actores.

El Gobierno del Distrito Federal, en junio del 2001, creó el Consejo de Consulta y Participación Indígena del DF. Consejo que forma parte de la Dirección General de Equidad y Desarrollo Social de la Secretaría de Desarrollo Social del DF. Este funciona 
como un órgano de asesoría, consulta, concertación y coordinación de la Administración Pública para la planeación, promoción, desarrollo y evaluación de políticas y programas de atención a los pueblos originarios y comunidades indígenas migrantes en el Distrito Federal, participa anualmente en la definición del Programa General de Atención a Indígenas del DF; vigila y evalúa el cumplimiento de dicho programa.

\section{Características formales}

Formalmente el consejo tiene como papel principal proponer las recomendaciones necesarias para fomentar y fortalecer la atención integral de los indígenas en el DF. Recomendaciones que tienen que ver con la planeación y programación de acciones públicas "encaminadas a elevar la calidad de vida de los indígenas en el Distrito Federal”. El Consejo está integrado por el Jefe de Gobierno del DF, los titulares de la Secretaria de Desarrollo Social, la Secretaría de Gobierno, la de Medio Ambiente y la de Desarrollo Económico; por un representante de la Procuraduría General de Justicia del DF, de la Subsecretaría de Trabajo y Previsión Social, de la Secretaría de Cultura, del Instituto de Vivienda del DF, la Dirección General de Regularización Territorial, las Delegaciones con mayor presencia indígena y los consejeros invitados: académicos de instituciones como El Colegio de México, el CIESAS; representantes de organizaciones o comunidades indígenas migrantes y originarias en el DF; organizaciones civiles que trabajen a favor de los indígenas del DF; representante del Tribunal Superior de Justicia del DF; representantes de la Asamblea Legislativa y el representante del INI, ahora Comisión de Asuntos Indígenas. Para el cumplimiento de sus funciones y actividades, este consejo conformó cuatro mesas de trabajo: Integridad Territorial; Equiparación Social y Acceso a Servicios Públicos; Legislación, Procuración de Justicia y Derechos Indígenas y la de Identidad y Convivencia Intercultural. Estas mesas se presentan, discuten y analizan diversas propuestas para que éstas sean presentadas ante el pleno del Consejo y se discuta su aprobación.

Este consejo representa un espacio de comunicación entre autoridades del DF y grupos indígenas ya que, es ahí donde se discuten y analizan todos los asuntos relacionados con la presencia de dichos grupos; y donde las autoridades pretenden otorgar cierta representación para que planteen los problemas que les aquejan y puedan defender sus puntos de vista y 
sus derechos. El objetivo de crear este espacio de comunicación ha sido el de diseñar un conjunto de propuestas sobre políticas públicas en materia indígena que, una vez presentadas y aprobadas por este consejo, se presenten en la Asamblea Legislativa para que sean consideradas en las modificaciones legislativas. El propósito es orientar una política pública que les permita a los grupos indígenas tener una mayor presencia a través de fomentar sus prácticas culturales, no sólo entre ellos mismos, sino que con el resto de la población e instituciones públicas.

Funcionamiento del consejo

Una característica importante de este consejo es que no sólo ha sido abierto para la participación de los grupos indígenas, sino para todos aquellos involucrados o interesados en las cuestiones relacionadas con dichos grupos, como son: instituciones académicas y organizaciones civiles. A partir de la labor que se realiza al interior se ha podido reflejar, de forma cuantitativa y cualitativa, la participación indígena así como las múltiples concepciones, intereses y expectativas de los actores que aquí se involucran.

Este consejo ha sido utilizado como un medio de expresión donde los grupos indígenas se acercan para exponer distintas problemáticas. Es de resaltar que los asuntos que se atienden tienen que ver con necesidades muy específicas que van desde el fomento a sus artesanía, programas de fortalecimiento a su lengua, eventos para la preservación y difusión de sus culturas, campañas de conscientización para disminuir la discriminación y promover el reconocimiento de la pluriculturalidad de la ciudad, una legislación especial para grupos en condiciones de vulnerabilidad; hasta la gestión de seguridad en sus trabajos, espacios reconocidos para ejercer el comercio ambulante, fuentes de trabajo, vivienda, salud, servicios, educación, etc.

A pesar de que este consejo fue instalado para abrir un espacio de reflexión y movilización en torno a la problemática de los derechos indígenas con énfasis en la singularidad de dichos derechos en el ámbito urbano; éste ha encontrado poca participación. En lo que respecta a las mesas de trabajo hay poca asistencia y los que acuden a las mesas programadas regularmente no son las mismas personas, por lo que es difícil que se puedan 
culminar propuestas debido a que las reuniones se tornan repetitivas y no se les puede dar seguimiento a los proyectos. Sucede que, en alguna ocasión, que se logró elaborar una propuesta ya no se estaba en tiempo para hacerla llegar a la Asamblea Legislativa. En general la sensación que prevalece entre los asistentes es que falta la participación tanto de autoridades de gobierno y académicas como de las mismas organizaciones indígenas. ${ }^{38}$

La escasa participación también se ve reflejada en las sesiones de este consejo donde, queja imperante de los asistentes es la poca afluencia de los indígenas a dichas sesiones. Actualmente, el consejo cuenta con un directorio de 47 organizaciones indígenas tanto del Distrito Federal como del Estado de México, en el que se encuentran los municipios de Nezahualcoyotl, Chimalhuacán, Valle de Chalco y Naucalpan. ${ }^{39}$ Haciendo un sondeo a partir de éste se puede constatar que existen algunas que no conocen de la existencia de este consejo y manifiestan que "se adornan con sombrero ajeno"; y otras que, además de no conocer la existencia de este consejo, se encuentran ya fuera de actividades, por lo que la participación real se reduce.

El consejo como espacio de intermediación entre ciudadano y gobierno donde se discuten problemáticas de fondo, como son el reconocimiento y la inclusión de sus derechos en las distintas leyes en el DF, pasan a segundo término, para discutir asuntos de carácter inmediato. En el tiempo que lleva instalado el consejo no se ha logrado incidir en las decisiones tomadas en la Asamblea Legislativa. Aunque no se deja de reconocer que sí han atendido demandas de vivienda, servicios médicos, regularización de actas de nacimiento, etc; sus principales actividades han estado encaminadas a difundir, promover, conservar y valorar la diversidad cultural del DF. Muestra de esto son el tipo de eventos que organiza: "Feria de la diversidad cultural", "Talleres de sensibilización indígena" en reclusorios y preparatorias, "Jornadas de convivencia intercultural", "Proyecto de comercialización de artesanía indígena”, muestras gastronómicas y artesanales, etc. ${ }^{40}$ El proyecto más importante que ha lanzado es el "Proyecto de Apoyo a Pueblos Originarios del DF 2004",

\footnotetext{
${ }^{38}$ Las anotaciones aquí hechas son resultado de mis observaciones durante mi participación en las mesas III. Legislación, Procuración e Impartición de Justicia y Derechos Indígenas; y V. Educación Intercultural.

${ }^{39}$ Publicado en la Gaceta Oficial del Distrito Federal el 8 de julio de 2003, pp. 11-14

${ }^{40}$ Informe de las mesas de trabajo durante la sesión del 27 de mayo de 2004.
} 
el cual estuvo dirigido a apoyar económicamente proyectos para el fortalecimiento de la cultura e identidad de pueblos originarios. ${ }^{41}$

Se sostiene que en general, los trabajos realizados en las mesas no han tenido incidencia en los espacios de decisión gubernamental. Esto ha provocado el desanimo de los participantes, tanto de instituciones académicas, de gobierno y organizaciones indígenas, el sentir general es que sólo se va a escuchar lo que dicen o hacer acto de presencia. Las sesiones ordinarias del consejo representan un espacio donde se informa sobre los trabajos y acuerdos del consejo, pero también un espacio de gestión donde se discuten cuestiones de comercio ambulante, lindes territoriales y problemas inmediatos.

Es un espacio donde se percibe una gran cordialidad y donde tanto organizaciones indígenas como autoridades se conocen y se tratan con tono amistoso e, incluso, paternal. Es importante resaltar que los representantes del consejo se dirigen por su nombre a casi todos los asistentes. Aunque los indígenas no ven en el consejo un espacio de resolución, sienten que deben hacer acto de presencia para darse a conocer.

En general, o a simple vista, se puede decir que, al existir un espacio formal de representación donde los grupos indígenas pueden acudir para dar a conocer tanto sus puntos de vista como sus necesidades y demandas como un grupo diferenciado, el gobierno está otorgando mecanismos de participación donde los distintos grupos puedan ejercer sus derechos ciudadanos. Pero, retomando las opiniones de los grupos indígenas involucrados en este consejo, éste no representa un espacio real de participación ya que, en general, no se les consulta sobre las decisiones que se toman ahí:

No es viable el consejo, porque ellos deben conocer nuestra demandas y propuestas, además es un consejo consultivo, no tiene la facultad de decisión (..,) ya tienen cocinado lo que van ha hacer. $^{42}$

\footnotetext{
41 Informe presentado en la sesión del 27 de mayo de 2004 . Igualmente se puede consultar en htto://www.sds.df.gob.mx/sector/c_indi.htm

${ }^{42}$ Entrevista realizada a representante de organización indígena. 14 de mayo de 2004
} 
Los indígenas no se sienten representados porque consideran que sus demandas no son consultas ni atendidas.

\section{b) Organizaciones indígenas}

Las organizaciones con las cuales se ha establecido contacto se pueden agrupar de la siguiente manera de acuerdo a sus características:

1) Representante zapoteco: Razón de asociación: lazos comunitarios o étnicos. Concentra personas de un solo grupo o, concretamente, de una comunidad ubicada en la sierra de Oaxaca. Sus labores están encaminadas a buscar apoyos entre sus miembros para mejoras en servicios para su comunidad de origen y la organización de las fiestas patronales. Guardan escasa relación con autoridades de gobierno, sus recursos los obtienen por medio de la organización de eventos culturales. No cuentan con un acta constitutiva, pero si cuentan con una organización interna para regular los ingresos y egresos y para la elección de los cargos.

2) Representante mazateco. Razón de asociación: gestiones para una colonia. Concentra a personas de varios grupos indígenas migrantes y originarios que tienen en común residir en una colonia de Milpa Alta. Sus funciones se concentraron en elaborar proyectos productivos (talleres de costura y elaboración de dulces cristalizados, limpia de terrenos de siembra, gestiones para obtener apoyos en útiles escolares, juguetes) para presentarlos a las autoridades correspondientes y ayudar económicamente a los integrantes. Buscan recursos en las diversas instancias del Gobierno del DF y también organizan eventos culturales. Cuentan con un acta constitutiva.

3) Representante mazahua: Razón de asociación: comercio ambulante. Concentra a mazahuas, otomies y nahuatls que venden en una calle del Centro Histórico. Se concentra en solucionar problemas de ambulantaje, principalmente, la defensa de sus lugares de venta.

Las organizaciones indígenas tienen como característica común la movilidad de sus miembros y representantes, al menos en los últimos dos casos mencionados, sus representantes han colaborado con cargos en otras organizaciones indígenas. Se agrupan 
como organización étnica en general, sin que la adscripción a un grupo específico sea determinante para su ingreso, su afiliación está más determinada por intereses comunes. Aunque las organizaciones estén jurídicamente diferenciadas, los miembros no lo están y pueden pasar de una a otra de acuerdo a los objetivos que persiga, incluso, una misma persona puede oscilar en dos organizaciones. Tal es el caso de una representante que pertenece a dos organizaciones, en una canaliza gestiones relacionadas con proyectos sobre lengua indígena u otro tipo de actividades y la otra está exclusivamente dedicada a la atención del comercio ambulante, en tono de broma comenta: "esta organización es virgen", 43 prefiere no mezclar los asuntos que no estén relacionados con el comercio en esta organización. Estas situaciones nos muestran que los indígenas en la ciudad se manejan en una red $^{44}$ que, además de unir a personas de un mismo grupo étnico y un objetivo determinado, une a un grupo que tienen objetivos comunes: defender "lo indígena" frente a un grupo dominante.

El estudio de las organizaciones indígenas nos lleva a considerar los tipos de relaciones que se mantienen al interior o los vínculos que las sostienen. Para el caso que nos ocupa es importante remitirnos a los tipos de relaciones sociales que distingue Max Weber:

- Una relación social será llamada comunitaria siempre y cuando la intención de la acción social (...) tenga como fundamento el que las partes experimenten el sentimiento subjetivo de pertenencia recíproca.

- Una relación social se denominará asociativa siempre que la acción social resulte de una articulación de intereses racionalmente determinada o de otro arreglo producido por causas similares (Weber, 1984).

Estas clasificaciones hacen alusión al tipo de vínculos que sirven de fundamento y que aglomeran a un determinado número de personas. Aquí se hace una clara separación entre una pertenencia subjetiva o de pertenencia y otra que apela a intereses concretos, la primera es algo superior al individuo ya que está dada desde antes de su nacimiento y la segunda, es

\footnotetext{
${ }^{43}$ Entrevista realizada a representante de organización indígena. 26 de abril de 2004

${ }^{44}$ El término red es entendido como campo social compuesto por relaciones entre personas. Todas las personas guardan relaciones con una serie de otras personas que, a su vez, están vinculadas a más personas, pero en su conjunto carecen de un dirigente o de una organización coordinadora, se pueden forma grupos o conjuntos pero todos los miembros siguen manteniendo sus relaciones. En este caso el criterio de unión que subyace a la red es lo étnico. (Mayer, 1990)
} 
cuestión de elección y está ligada a las necesidades de la existencia social. En los casos que analizamos esto es importante porque en las organizaciones indígenas encontramos que estos dos tipos de relación se traslapan y coexisten en un determinado grupo que se reúne y estratégicamente construye un discurso que alude a dicho sentimiento comunitario, ${ }^{45}$ pero que en la práctica están vinculados porque comparten un interés común que tiene que ver con necesidades reales y específicas producto de la desigualdad social que padecen.

\title{
5. Conclusiones
}

\subsection{Relaciones interétnicas y construcción de la identidad}

Haciendo un balance de la labor que ha desempeñado el consejo y las expectativas de las organizaciones indígenas, podemos observar que éste no ha alcanzado a satisfacer dichas expectativas y ni a significado un espacio de representación o decisión al cual puedan acceder para ser escuchados. Mientras que el consejo, en una actitud paternalista, tiene la idea de cuidar, proteger y revalorar el patrimonio cultural indígena; el indígena, más que pretender difundir y preservar su cultura, acude con necesidades muy concretas como la defensa de espacios de ambulantaje. Muestra de esto es el hecho de que mientras en el consejo se prepara un proyecto de fomento a la artesanía, ${ }^{46}$ la representante de una organización mazahua comenta: ${ }^{47}$

\begin{abstract}
"Se les olvidan dos ejes: los artesanos elaboran su propia artesanía, y es un respeto, pero para nosotros, el pueblo mazahua, nosotros ya no elaboramos. Nos dedicamos a, se puede decir desde el origen, que he estado leyendo el origen de mis antepasados, es una cultura que traemos de vender desde nuestro origen en la ciudad de México, los primeros que llegaron a vender fueron otomies, nahuas y mazahuas (...)se le está dando prioridad a los compañeros que son artesanos, efectivamente porque ellos elaboran, pero algo importante, a lo mejor nosotros no nos hemos tenido los elementos para defender una postura, de que los primeros que llegaron aquí en el Distrito Federal a vender sus artesanías fueron los Otomíes, los Mazahuas y los Náhuatls (...) Dos, nosotros de los setentas para acá, nosotros nos hemos dedicado al comercio de que era de varios; palanquetas, pepitas, chicharrones, papas y la fruta de temporada. La fruta de temporada, el tiempo de elote, el tiempo de las tunas, el tiempo de mango, el tiempo de la fruta. Para eso no hay reconocimiento. Efectivamente, no hay el reconocimiento, pero yo creo que como decía, por eso en una de las peticiones que nosotros hemos hecho, es de que se vea la antigüedad (...) Entonces, yo creo, tenemos que hacer, como decía, un diagnóstico para también presentarlo al
\end{abstract}

\footnotetext{
${ }^{45}$ Este sentimiento comunitario está dado por los vínculos surgidos del parentesco, la vecindad o territorio, la lengua común, la religión común y las costumbres comunes.

${ }^{46}$ Este proyecto tiene como objetivo crear talleres de comercialización (donde se discutan los mecanismos de comercialización, los procedimientos para la obtención de código de barras y procesos de mercadotecnia), exportación de mercancías, elaboración de un catálogo, conformación de empresas sociales, certificación de calidad. Proyecto presentado en la sesión del 27 de mayo de 2004.

${ }^{47}$ Comentario hecho con respecto al proyecto, durante la sesión del 27 de mayo de 2004
} 
Consejo, yo creo que a nosotros como Mazahuas porque, no sé, bueno, yo al menos digo, artesanías sí, pero nosotros como Mazahuas ¿qué?, nosotros de hacer talleres, de aprender, de volver a hacer los bordados, ya no. Por qué, porque es muy laborioso, es mucho trabajando. Mejor a veces, por qué cree que a veces mejor compañeros prefieren ir a vender chicles en un ratito y sacan lo que se ganan, en un ratito.

En la construcción de las identidades este hecho nos muestra la existencia de dos discursos sobre lo étnico. ${ }^{48}$ Por un lado, el consejo está pensando y proyectando actividades dirigidas a la preservación y difusión de los elementos culturales que caracterizan a los grupos indígenas, sin considerar que éstos han sufrido transformaciones, por motivos en ocasiones ajenos a ellos, que los han llevado a el abandono de ciertas costumbres y rasgos que los caracterizaban, en este caso, la elaboración de artesanías. Por su lado, las organizaciones indígenas, en este discurso de defensa de las características étnicas, apelan o construyen otras tradiciones, inventadas en el sentido de Giddens, como es el comercio en vía pública, para defender sus posiciones. El comercio en vía pública es convertido en un elemento cultural que caracteriza a su grupo.

Retomando la teoría de los campos de Bourdieu podemos pensar que esta exaltación de lo indígena como un medio para obtener determinados beneficios, está siendo alimentado por los mismos discursos de gobierno que, más allá de considerar el estado actual en el que se encuentran los grupos que convergen en la ciudad, está tratando de que el reconocimiento de la diversidad cultural. Los indígenas aprovechan este ambiente de reconocimiento para acceder a determinados recursos de la ciudad, en nombre de esta revaloración de la cultura indígena.

En esta idea de la construcción de la cultura y la identidad a través de las relaciones sociales, vemos como el mismo gobierno ha participado en esta "nueva" exaltación de lo indígena. La investigación de campo ha arrojado que los representantes de las

\footnotetext{
${ }^{48}$ Mientras el gobierno manifiesta su idea o intento por difundir "la riqueza de la diversidad cultural del DF". Los representantes de dicha diversidad están buscando apoyos que no tienen que ver con riqueza cultural. Intentan obtener lugares para le venta de sus mercancías. Mercancías que no son necesariamente artesanías, como pretende el discurso de gobierno, sino artículos diversos o, incluso, producto de la piratería o la falluca (relojes, muñecas de porcelana importadas de China, discos, cigarros, útiles). Esto bajo el argumento de que la remuneración económica que obtienen es muy baja y el costo, tanto monetario como físico, tan alto: "nosotros bordamos con punto de cruz, pero es muy desgastante su elaboración". Entrevista a representante de organización indígena 26 de abril de 2004.
} 
organizaciones indígenas aseveran que es a partir de Foros sobre derechos indígenas, convocados por instancias de Gobierno, en este caso el Instituto Nacional Indigenista, como han empezado a revalorar sus raíces étnicas y a organizarse:

ahorita como me estoy expresando, si en esos años me hubiera expresado así, pues a la mejor íbamos a tener todo Centro Histórico, pero pus antes con que tu dijeras yo voy a ir a vender, si vendí bien si no, no; esto no le interesaba a los demás. Pero yo pienso que esta lucha social que yo llevo me he involucrado por los talleres que he tomado de derechos indígenas, pues yo me imagino que por eso, si porque luego digo: pobrecitos, este, no son pobrecitos, somos pobrecitos todos. Por lo menos puedo ayudar algo, logré los espacios para varias compañeras, logramos becas para los niños, logramos carnets para atención medica. Después del encuentro que hicimos (Foro) logramos este mejoramiento de vivienda, varias cosas, no me quejo, bien o mal así como me expreso. A partir de ahí es donde sentí que me involucré en los derechos indígenas, que un indígena, por decir, anteriormente pues yo ya sabía que no me iban ha atender en una clínica, pues mejor me iba a un doctor particular. Pero ya después, cuando tomamos las garantías individuales, pues ahí dice que tengo derecho de la educación, de una vivienda digna, derecho de la justicia, derecho de una vivienda, ósea, todo ¿no?, pues si aquí está, lo único que hay que hacer es cumplir eso y, entonces al conocer eso, dice ahora pues meto esa propuesta solicitamos trescientas carnets para la gente indígena y ahí están los carnets. ${ }^{49}$

Es a partir de reconocimiento que perciben por parte del gobierno y de su entorno social como se inicia la revaloración de sus culturas:

Nosotros hacíamos de alguna manera gestiones, pero muy así, cómo se puede decir, muy primitivos, hacíamos las gestiones como nos diera a entender, el chiste es de que saliera el trabajo. Pero eso no lo sabía el gobierno ni nadie. Pero el gobierno pensó en eso, el gobierno del PRD, se puede decir de Rosario Robles; pensó que los indígenas tenían derecho y que tenían que conocer sus derechos más todavía, y sacaron la convocatoria y llegamos allí y ya nos empezaron, pues, nos empezaron a enseñar otras cosas. Querían que fuéramos abogados indígenas, pero no se porqué no se concretó en aquel entonces. Porque el gobierno decía que, conjuntamente con la Universidad Nacional Autónoma de México, querían que fuéramos a un curso todavía más, cómo se pude decir, más amplio, como especializarnos más en cuestiones de derecho para que nosotros fuéramos como abogados (...) en ese curso nos dieron bastante información, creo que no se nos quedó todo lo del curso, no, porque fue impactante o fue mucha información, bueno, para nosotros que pensábamos que nada mas nos iban a enseñar cómo redactar un oficio. ${ }^{50}$

\section{Esta misma revaloración la perciben en su entorno social:}

Sí nos hacen descuentos, sí nos hacen descuentos porque la moda está lo que es indígena (...) Pues la moda digo, como que la gente de la ciudad lo agarró así como moda, ¿no?, como que diciendo: pobres indígenas todavía existen (risas). Antes no, antes como, como que nos veían feo, cuando íbamos en la pesera y empiezas hablar con tu compañero en tu lengua indígena y

\footnotetext{
${ }^{49}$ Entrevista a representante indígena el 14 de mayo de 2004

${ }^{50}$ Entrevista a representante de organización indígena. 26 de abril de 2004.
} 
como que te volteaban a ver muy feo, pero ahora, al contrario, si vas platicando hasta te preguntan ¿de dónde eres? o ¿qué lengua indígena, que idioma es eso? (...) Sí, y ahora, ya las mismas autoridades andan difundiendo que tenemos derechos, lógico algunos de nosotros siempre hemos sabido que tenemos derechos, pero no todos, le digo, y eso ha causado que, por ejemplo, las dependencias, por ejemplo, este, las dependencias ya sepan, ya sepan, de que, este, difundan mucho, bueno, al menos este gobierno, el perredista que está ahorita, desde Cárdenas, desde Cárdenas, bueno, al menos nosotros sí hemos sentido eso, que sí ha apoyado mucho las cuestiones indígenas, aunque sea la difusión y todo eso, la prueba está en el curso que recibimos pues que viene del ingeniero Cárdenas. A partir de ahí, pues, yo no se sí en todos los estados de la republica, pero aquí está muy fuerte las cuestiones indígenas. ${ }^{51}$

La forma en la que el indígena se está definiendo y percibiendo a sí mismo, parte del significado que éste le está dando a su relación con las instancias gubernamentales. Como lo muestran los casos anteriores, el gobierno ha jugado un papel muy importante en el resurgimiento de lo indígena en los espacios públicos. El indígena enalteciendo los rasgos culturales que lo definen, como su lengua o su vestimenta, es un fenómeno producto de la forma en que está reinterpretando la relación que tiene con su entorno ${ }^{52} \mathrm{y}$, específicamente, su relación con el gobierno. La revaloración de lo indígena por el indígena parte de este reconocimiento y orgullo que manifiesta y promueven las respectivas instancias gubernamentales.

Es a partir de definir e interpretar la forma en que se está siendo percibido por el otro, en este caso, el gobierno, como los indígenas están determinando sus acciones y la forma de percibirse a sí mismo. Esta reinterpretación está reflejada en las muestras de orgullo fundado en un esencialismo que hace exaltar sus raíces y sus rasgos culturales. Esta exaltación no sólo tiene como finalidad el reconocimiento, tanto interna como externamente, de la herencia cultural indígena sino, es mezclada o utilizada con otros objetivos como el de acceder a ciertos recursos que les permitan combatir la desigualdad social y económica que padecen. En este caso su herencia indígena es un medio para

\footnotetext{
${ }^{51}$ Entrevista a representante de organización indígena. 26 de abril de 2004.

${ }^{52}$ Es importante aclarar que aunque apelan al legado histórico que heredaron como su lengua, tradiciones, vestimenta, etc.; en ocasiones refieren no conocer el verdadero significado de estos. Ejemplo de esto es un encuentro espontáneo entre una representante indígena y un extranjero quien le comenta sobre la belleza de su vestimenta y alude al significado de los colores que porta: amarillo representa al sol, el verde a la naturaleza y el blanco la pureza. La representante refiere haberse sorprendido por el cometario ya que no había considerado esos significados. Posteriormente, adopta dicha explicación para referir a la importancia y belleza de su vestimenta. Entrevista a representante indígena. 14 de mayo de 2004
} 
obtener mejoras en el ámbito económico, como son: vivienda, salud y, en especial en los casos que estudiamos, espacios de venta en vía publica. Como el caso que mencionamos con anterioridad y el siguiente donde se discute sobre la reubicación del ambulantaje en el centro histórico y las propuestas que tiene la organización indígena:

La propuesta que estamos haciendo ahorita para el Centro Histórico, el que porte su vestimenta, el que hable una lengua son los que van ha ser respetados. No lo quería decir porque es un secreto, son cosas que queremos hacer para que también el gobierno se de cuenta que sí los estamos apoyando, pero que también nos respete. Y entonces, por eso, nosotros por ahí vamos, porque también a nosotros nos perjudica mucho los que realmente no son indígenas y, también va haber otro secreto ahí que no quiero que lo saque, hay líderes grandes de que tienen hasta últimos modelo, bueno, carros de último modelos y tienen cuántos chalanes, trabajadores, que les están pagando, nadamás fíjese, se agarran la mera esquina, y entonces dice, hay unas personas que, por decir, líderes, que pueden tener hasta 30, 20 puestos, son chalanes y ya los meten como titulares y, entonces, eso nos afecta porque crece el ambulantaje, si trabajaran como nosotros que realmente resentimos porque de ahí sacamos para comer, no estuvieran todos los comerciantes ambulantes que ustedes ven en la calle, fuéramos menos. ${ }^{53}$

El tipo de relación que han entablado ambos actores han puesto de manifiesto los límites y oportunidades de que dispone cada actor involucrado, en función del conocimiento o balance que el actor realice de éstos, serán fundamentales en la definición de sus acciones. Esto nos muestra otro nivel o ámbito de la relación indígenas/gobierno donde, la identidad étnica se convierte en una herramienta o un elemento negociable en el intercambio por los recursos materiales. Considerando las características de esta relación, esbozadas con anterioridad, el caso antes expuesto pone de manifiesto la idea de que, cuando está en juego la lucha por los medios de sobreviencia, es totalmente válido la utilización de ciertos elementos étnicos que definen sus pertenencias. El ejemplo anterior refleja la existencia de una lucha y competencia por los recursos económicos. En esta competencia la pertenencia étnica juega un papel de suma importancia ya que se transforma en un elemento negociable para acceder a dichos recursos.

Estudiando las experiencias de los grupos indígenas hemos podido constatar cómo las relaciones interétnicas han construido la forma en que se perciben a sí mismos, es decir; han construido su identidad. Podemos observar que en el pasado cuando el país pretendía unificar una nación y fomentar el desarrollo, las políticas de mestizaje que se promovieron

${ }^{53}$ Entrevista a representante de organización indígena. 14 de mayo de 2004 
estuvieron encaminadas a desaparecer las culturas indígenas, era una época en la que lo mejor era ser mestizo y en la que los mismos indígenas, como parte de esa difusión de lo indígena como sinónimo de atraso, prefirieron hacer a un lado e, incluso, esconder sus rasgos culturales. ${ }^{54}$ En las actuales circunstancias donde se enarbolan los discursos sobre la instauración de la democracia en nuestro país y, en el caso del DF, con la instalación del "primer gobierno democrático", al menos en el ámbito electoral, hablar de la diversidad cultural y su revaloración sirve mucho para los discursos democráticos. Es en función de la interpretación de estos discursos como han definido su actuar.

La percepción que tienen de sí mismos se ha transformado adecuándose a las nuevas circunstancias. Estas transformaciones las podemos observar en el hecho de que, según los casos estudiados, por mucho tiempo se dejó de usar la vestimenta tradicional, ${ }^{55}$ esto debido a las políticas de mestizaje que propagaban la idea de que ser mestizo era mejor. Ahora, después de los cursos y talleres que impartieron distintas instancias de gobierno donde se promueven sus derechos y la "revaloración de lo indígena", vuelven a vestir sus trajes tradicionales y hablar su lengua. ${ }^{56}$

\footnotetext{
54 Este discurso viene desde la época del nacionalismo en México. El nacionalismo en su afán por homogeneizar y construir una nación, no consideró en sus proyectos al indio, los proyectos de Estado estuvieron encaminados a las campañas de mestizaje que buscaban desparecer al indio por medio de la asimilación. Pero la construcción de una nación no sólo tenía como objetivo la unificación cultural, de hecho esta unificación también partía de una ideología occidental que predicaba que para alcanzar el bienestar económico o el "progreso" había que conformar una nación. (Gellner, 1988) En este sentido el indio representaba lo no moderno, lo arcaico una reliquia que la nación mestiza debía olvidar y trascender. "No se puede ser moderno sino dejando de ser tradicional; no se puede mirar al futuro sino dejando de mirar al pasado; no se puede ser universal sino dejando de ser diferente y particular" (Giménez, 1987:155) Los indígenas tuvieron que enfrentarse a las fuerzas del progreso y la unificación nacional que los obligó a esconder sus rasgos culturales e intentar asimilarse a la cultura mestiza.

${ }^{55}$ Las políticas de mestizaje que tenían como finalidad desaparecer los rasgos indígenas provocaron que muchos, para evitar la discriminación social, imitaran las costumbres o características culturales del mestizo.

${ }^{56}$ Una entrevistada manifiesta que dejó de usar su atuendo por muchos años porque tenía que acudir a la escuela de sus hijos y si la veían con su traje después se burlaban de sus hijos. Después de los cursos que tomó y de revalorar su propia cultura decidió vestir nuevamente su atuendo tradicional y, aunque sus hijos en ocasiones le piden que no se "ponga el disfraz" ella no lo deja de hacer y les dice que los disfrazados son ellos "el mío es original". Igualmente, manifiesta que sus hijos portan el traje tradicional sólo en ocasiones especiales, como las fiestas religiosas de su comunidad. Entrevista realizada el 14 de mayo de 2004. Además, es común que en distintos espacios, tanto de gobierno como académicos, asistan con sus atuendos tradicionales y sus intervenciones las inicien con saludos en su lengua. Cuando no lo portan es común que se justifiquen diciendo que es por comodidad.
} 
La exaltación de sus rasgos culturales, como la vestimenta y la lengua, son resultado de un nuevo discurso tanto académico como de gobierno, dirigido a la defensa y preservación las culturas indígenas. Pero este discurso no es creación exclusiva del gobierno, sino que también está siendo alimentado y sustentado en el ámbito académico. En dicho ámbito resulta incuestionable la existencia de la utilización estratégica de determinados elementos indígenas. La esencia indígena parece no estar a discusión. En este espacio lo étnico representa algo puro y estático que no se somete o se expone a las nuevas circunstancias sociales que enfrentan. Hablar de la "manipulación estratégica" de lo étnico genera, incluso, molestia. ${ }^{57}$ Esto tiene fundamento en el hecho de que dentro de un seminario que tiene entre sus objetivos:

Promover la investigación, el intercambio, el análisis y el debate sobre la temática de la ciudad, la etnicidad y la diversidad cultural; consolidar la producción de conocimiento sobre la ciudad y su diversidad cultural como un ámbito estratégico en el Distrito Federal y como componente fundamental para la formulación de políticas públicas en la materia; y fomentar la realización de investigaciones originales y novedosas sobre la relación ciudad, pueblos indígenas y etnicidad. $^{58}$

Cuando se presenta un académico con una propuesta que hace alusión al hecho de que el tránsito entre un discurso sobre el campesinado y otro que pone el acento en lo indígena, tiene que ver con las necesidades que el mismo sistema impone, es decir, el énfasis puesto en cada discurso "se esgrimen situacional y relacionalmente". "En un ambiente donde ser mestizo es lo mejor, el indígena desaparece. Hoy la etnicidad, no requiere de un sustrato

\footnotetext{
${ }^{57}$ Los comentarios vertidos en esta parte tienen como fundamento observaciones hechas durante las sesiones del "Seminario Permanente: Ciudad, pueblos indígenas y etnicidad", convocado por la Dirección de Equidad y Desarrollo de la Secretaria de Desarrollo Social del DF, la Universidad de la Ciudad de México y el CIESAS. En este seminario, iniciado en el 2002, se han presentado 24 ponencias que versan sobre temas relacionados con: identidades étnicas; formas y experiencias organizativas de los pueblos y comunidades indígenas; el concepto de territorio de los pueblos originarios, de las comunidades residentes y de los migrantes indígenas; formas de vinculación; mercado laboral; convivencia intercultural; la diversidad y la política pública del gobierno de la Ciudad de México; naturaleza y alcance de los derechos indígenas, etc. todos en relación con los ámbitos urbanos. Según mis propias observaciones, todas con un tinte de promoción y defensa que parte de considerar la desigualdad y marginación social que han padecido históricamente para, posteriormente, enfatizar en la necesidad de reconocer la riqueza cultural de nuestra nación y, en función de esto, crear los mecanismos necesarios que permitan salvaguardar sus formas de vida y sus derechos en todos los ámbitos. Sobre los contenidos de estas ponencias se puede consultar la página de internet: http://www.sds.df.gob.mx/sector/c_indi.htm

${ }_{58}$ Para consultar sobre los objetivos del seminario consultar la página de internet: http://www.sds.df.gob.mx/sector/c_indi.htm
} 
campesino, requiere de un soporte cultural". 59 Sostener que el hecho de que los campesinos desaparezcan del discurso y surja la etnicidad es resultado de una manipulación estratégica que los sujetos elaboran; genera entre sus asistentes, no sólo silencio, dudas y cuestionamientos sobre el fundamento de sus aseveraciones; sino un cierto tono de molestia entre los mismos anfitriones.

Podemos observar que en el ámbito académico el resurgimiento de lo étnico tiene cabida y es alimentado por los mismos investigadores. Dicho ámbito se presenta como un espacio donde no es válido cuestionar lo indígena y donde se intenta preservarlo como algo esencial, puro e inamovible. Las posturas tanto académicas como de gobierno, construyen un discurso del "buen salvaje". Postular la instrumentalidad de lo indígena parece no estar a discusión. El indígena adaptado y consciente de los espacios en los que se mueve, de sus posibilidades y límites que le ofrecen las circunstancias actuales, no existe. La propagación de estas concepciones, es muestra de la labor académica y sus influencias en la forma en que se está construyendo el discurso indígena.

La etnicidad es producto de la forma en que están interactuando los distintos grupos que operan dentro de contextos sociales comunes y, como producto de esa interacción, no son definitivas sino situacionales. En el contexto que estudiamos, donde el acceso a los recursos es desigual y limitado, la etnicidad se enarbola como una estrategia para competir por los recursos materiales que ayuden la sobrevivencia. La desigualdad social que prevalece en la sociedad se cubre con un discurso sobre lo étnico.

El estudio de la construcción de discursos, tanto de las autoridades como de los académicos, permiten observar cómo estos generan las circunstancias adecuadas para que los grupos indígenas entren en escena y, a partir del análisis de las posibilidades y límites que imponen dichas circunstancias, satisfacer determinados intereses. Los discursos y prácticas que se expresan en estos espacios sociales permiten delinear las representaciones que cada actor tiene uno con respecto del otro. Es a partir de la interpretación que hacen de dichas representaciones como los actores valoran y definen sus acciones.

\footnotetext{
${ }^{59}$ Ponencia presentada en la sesión del 8 de junio de 2004
} 
La construcción de identidades y sus expresiones, tanto objetivas como a nivel simbólico, se vuelven accesibles a través de los espacios políticos. Es en este espacio de interacción donde se manifiestan los acuerdos y desacuerdos; y donde se debaten y negocian los intereses en juego. Retomar el análisis de estos espacios nos permite entender la forma en que están definiendo su actuar. Aunque la investigación de campo es aún somera, nos permite marcar algunas líneas que ayudan a explicar el comportamiento de los sujetos de estudio. 


\section{Bibliografía}

Arizpe Lourdes (1975), Indígenas en la ciudad de México. El caso de las Marías, México, SEP/Setentas.

Arizpe, Lourdes (1985), Campesinado y migración, México, SEP.

Barth, Frederick, Los grupos étnicos y sus fronteras, México, FCE, 1976.

Baud, Michiel et al., Etnicidad como estrategia en América Latina y el Caribe, Quito, Abyala-Yala, 1996.

Bonfil, B, G. (1987), "Los pueblos indios, sus culturas y las políticas culturales”, Nestor García Canclini (edit.), Políticas culturales en América Latina, México. Grijalbo.

Bourdieu, Pierre, Sociología y cultura, México, Grijalbo, 1990

Bourdieu, Pierre, Cuestiones de sociología, Madrid, Istmo, 2000.

Cardoso de Oliveira, Roberto, Etnicidad y estructura social, México, CIESAS, 1992

Castells, Manuel, La era de la información. Economía, sociedad y cultura, vol. II, El poder de la identidad, Madrid, Alianza Editorial, 1998.

Clifford, James, Dilemas de la cultura, México, Gedisa, 1995

Cuche, Denys, La noción de cultura en ciencias sociales, Buenos Aires, Nueva Visión, 1996

De la Peña, Guillermo, "Notas preliminares sobre la 'ciudadanía étnica' (el caso de México)", Alberto Olvera (coord.), La sociedad civil, de la teoría a la realidad, México, COLMEX, 1999.

De la Peña, Guillermo y Regina Martínez, "Migrantes y comunidades morales: resignificación, etnicidad y redes sociales en Guadalajara", Ponencia para el Seminario Permanente Ciudad, pueblos indígenas y etnicidad, México, GDF/CIESAS, 2002

Díaz-Polanco, Héctor, La cuestión étnico-nacional, México, Fontanara, 1988.

Díaz-Polanco, Héctor, "El viejo conflicto: autonomía y liberalismo”, Leticia Reina (coord.), Los retos de la etnicidad en los estados-nación del siglo XXI, México, INI/CIESAS/Porrúa, 2000.

Durkheim Emile, Las reglas del método sociológico, México, Ediciones Quinto Sol, 1990 
García Canclini, Nestor, Culturas híbridas. Estrategias para entrar y salir de la modernidad, México, Grijalbo, 1989.

Gellner, Ernest, Naciones y nacionalismos, México, CONACULTA/Alianza, 1988.

Giglia, Angela, "Minorías”, Laura Baca Olamendí, Judit Bokser-Liwerant, et al. (comps.), Léxico de política, México, FLACSO/CONACYT/FCE/Fundación Heinrich Böll, 2000.

Giddens, Anthony, Un mundo desbocado. Los efectos de la globalización en nuestras vidas, México, Taurus, 1999.

Giménez Montiel, Gilberto, La teoría y el análisis de la cultura, México, SEP/Universidad de Guadalajara/COMECSO, 1987.

Giménez Montiel, Gilberto, “Identidades étnicas: estado de la cuestión”, Leticia Reina (coord.), Los retos de la etnicidad en los estados-nación del siglo XXI, México, INI/CIESAS/Porrúa, 2000.

Giménez Montiel, Gilberto, "Globalización y cultura”, Estudios sociológicos, vol. XX, núm. 58, El Colegio de México, enero-abril, 2002, pp. 23-46.

Geertz, Clifford, La interpretación de las culturas, Barcelona, Gedisa, 1987.

Hannerz, Ulf (1993), Exploración de la ciudad, México, Fondo de Cultura Económica.

Hiernaux-Nicolas, Daniel, Metrópoli y etnicidad. Los indígenas en el Valle de Chalco, México, El Colegio Mexiquense/FONCA/Ayuntamiento de Chalco, 2000.

INEGI, Tabulados básicos. Estados Unidos Mexicanos. XII Censo General de Población y Vivienda, 2000, México, INEGI, 2001.

Kymlicka, Will y Wayne Norman, "El retorno del ciudadano. Una revisión de la producción reciente en teoría de la ciudadanía”, Ágora. Cuaderno de Estudios Políticos, núm. 7, 1997.

Kuper, Adam, Cultura. La versión de los antropólogos, Barcelona, Paidós, 2001.

Iracheta Cenecorta, Alfonso, "Gobernabilidad en la Zona Metropolitana del Valle de México", Papeles de población, Año 9, núm. 36, abril-junio, Centro de Investigaciones y Estudios Avanzados de la Población/UAEM, 2003.

Mayer, C, Adrián, "La importancia de los cuasi-grupos en el estudio de las sociedades complejas", Eric R. Wolf, J. Clyde Mitchell, et. al, Antropología social de las sociedades complejas, Madrid, Alianza, 1990 
Melucci, Alberto, Acción colectiva, vida cotidiana y democracia, México, El Colegio de México, 1999.

Mires, Fernando, "La pasión política (aportes para una ética política post-moderna)", Espacio abierto, vol. 10, núm. 4, Venezuela, octubre-diciembre, 2001, pp. 499-549.

Mouffe, Chantal, El retorno de lo político. Comunidad, ciudadanía, pluralismo, democracia radical, Barcelona, Paidós, 1999.

Oehmichen B., Cristina, Mujeres indígenas migrantes en el proceso de cambio cultural. Análisis de las normas de control social y relaciones de género en la comunidad extraterritorial, Tesis de doctorado, México, IIA-UNAM, 2001

Oehmichen B., Cristina, "La multiculturalidad en la ciudad de México y los derechos indígenas", Ponencia para el Seminario Permanente ciudad, pueblos indígenas y etnicidad, México, GDF/CIESAS, marzo de 2003.

Rawls, John, "Justice as Fairness: Political not Metaphysical", Philosophy and Public Affairs, vol. 14, núm. 3, 1985.

Reina, Leticia, Los retos de la etnicidad en los estados-nación del siglo XXI, México, INI/CIESAS/Porrúa, 2000.

Rosaldo, Renato, Cultura y verdad. Nueva propuesta de análisis social, México, CONACULTA/Grijalbo, 1991.

Sartori, Giovanni, La política. Lógica y método en las ciencias sociales, México, FCE, 2003.

Tejera Gaona, Héctor, "Vecinos, identidades locales y participación ciudadana en la ciudad de México: la experiencia de los comités vecinales", Ensayos, México, Instituto Electoral del Distrito Federal, 2003

Tejera Gaona, Héctor, "No se olvide de nosotros cuando esté allá arriba”: cultura de la política, campañas electorales y demandas ciudadanas en el Distrito Federal, Tesis de Doctorado, México, Universidad Iberoamericana, 1999.

Touraine, Alain, ¿Qué es la democracia?, México, FCE, 2001

Valencia Rojas, Alberto, La migración indígena a las ciudades, México, INI/Programa para las Naciones Unidas para el Desarrollo, 2000.

Wallerstein, Immanuel, Después del liberalismo, México, Siglo XXI, 1996. 
Warman, Arturo y Arturo Argueta (coords.), Movimientos indígena contemporáneos en México, México, CEIIH-UNAM/Porrúa, 1993.

Weber, Max, El político y el científico, Madrid, Alianza, 1967.

Weber, Max, La acción social: ensayos metodológicos, Barcelona, Península, 1984 